\title{
Paläolithische Kulturen und Pleistozäne Stratigraphie in Süddeutschland
}

\author{
Von Hansjürgen Müli.er-Beck, Bern \\ Mit 5 Abbildungen im Text
}

Zusammenfassung: Die paläolithischen Inventare Süddeutschlands können wie folgt stratigraphisch gegliedert werden:

1. Frühpaläolithische Begehung im Ausgang einer längeren altpleistozänen Warmphase, wahrscheinlich unmittelbar vor dem „ältesten Löß" Süddeutschlands. Geröllgeräte von Mauer.

2. B e gehung ausgangs der nächstjüngeren Warmzeit. Altertümliche Abschlaginventare des Altpaläolithikums.

3. B e gehung in einer interstadialen Schwankung der anschließenden Kaltphase. Etwas entwickeltere Abschlaggeräte mit schwacher Faustkeilkomponente.

4. B egehung kurz vor oder im Beginn des letzten Interglazials. Spuren des Faustkeilschaberkreises.

5. B e gehung im oberen Abschnitt der gleichen Wärmeperiode. Mousteroide Artefakte mit beginnender Blattspitzentendenz.

6. Altpaläolithische $S t u f e$ (Fortführungder 5. Begehung) im Übergang zur letzten Kaltzeit. Einfache Inventare des Oberen Altpaläolithikums, Altpaläolithikum mit Blattspitzen, altpaläolithische Gruppen mit stark gesteigerten Kratzeranteilen. Haldensteinklinge als Obergrenze des Altpaläolithikums.

1. Jung paläolithische Begehung im Bereich und möglicherweise vor der Hauptschwankung der letzten Kaltzeit (Hauptschwankung, weil eine ältere - außerhalb Süddeutschlands belegbare - kleinere Oszillation und zumindest zwei jüngere Schwankungen innerhalb der letzten Kaltphase wahrscheinlich sind). Unteres, dem westlichen Aurignacien I sowie ähnlichen östlichen Einheiten anschließbares Jungpaläolithikum.

Fortgesetzte B egehung im Oberen Würm durch verschiedene, überwiegend östlich orientierte jungpaläolithische Gruppen bis ins Spät- und Postglazial und Úbergang zum Mesolithikum, ohne ausgeprägte Diskordanz zwischen Jungpaläolithikum und Mesolithikum.

Die Einordnung in das allgemeine stratigraphische System des süddeutschen Pleistozäns kann nur mit Vorbehalt und unter Beiziehung einiger terminologischer Hilfsbegriffe durchgeführt werden: Die 1. Begehung steht am Ende einer zeitlich ausgedehnten Warmzeit, die nach unten durch Don a und gegen oben durch die "N"-Kaltzeit abgegrenzt erscheint und die Deckenschotter als "G“- und "M“-K ä 1 t e oszill a t i o n e n unbekannter Größenordnung in sich einschließt. Die 2. Begehung wird dem Ausgang des Steinheimer Interglazials zugeteilt, während die 3., 4. und 5. mit der folgenden " $\mathrm{R}^{\text {“ }} \mathrm{K}$ K $1 \mathrm{lt} \mathrm{z}$ e it und dem anschließenden "Stut tgarter Intergla zial " in Verbindung stehen. Das restliche Altpaläolithikum sowie das gesamte Jungpaläolithikum gehören dem W ü $\mathrm{rm}$, das Mesolithikum dem fr üh en Holozän an.

Rés umé: Les inventaires paléolithiques de l'Allemagne du Sud peuvent être divisés stratigraphiquement de la manière suivante:

Première fréquentation humaine à la fin d'une longue phase chaude du Pleistocène inférieur, probablement immédiatement avant le "Löss ancien" de l'Allemagne du Sud. Instruments sur galets de Mauer près Heidelberg.

Deuxième fréquentation humaine à la fin de la période chaude suivante. Industrie sur éclats d'aspect antique du Paléolithique inférieur.

Troisiéme fréquentation humaine pendant un interstadiaire de la période froide subséquente. Industrie sur éclats un peu plus évoluée avec une faible composante de bifaces.

Quatrième fréquentation humaine immédiatement avant ou au commencement du dernier interglaciaire. Traces du "Faustkeilschaberkreis" (Abb. 2).

Cinquième fréque n $\mathrm{tat} \mathrm{t}$ ion hum in e vers la fin de cette même période chaude. Instruments moustéroïdes avec apparition d'une tendance vers les pointes foliacées. 
Sixième phasedu Paléolithique inférieur (continuationde la cin$\mathrm{q} u \mathrm{i}$ è $\mathrm{me}$ ) au passage à la dernière période froide. Inventaire simple de la fin du Paléolithique inférieur, Paléolithique inférieur avec pointes foliacées, groupes du Paléolithique inférieur avec un pourcentage très augmenté de grattoirs, lame du type "Haldenstein" comme limite supérieure du Paléolithique inférieur.

Premièrefréquentation humaine du Paléolithique supérieur dans et peut-être déjà avant l'interstadiaire de la dernière période froide (interstadiaire principal, parce qu'il est probable que cette dernière période froide a connu en outre une petite oscillation antérieure - constatée en dehors de l'Allemagne du Sud - et au moins deux autres oscillations plus récentes). Paléolithique supérieur commençant qui peut être rattaché à l'Aurignacien I occidental et à des industries analogues de l'Est.

Continuation de la fréquentation humaine au cours du Würm supérieur. Différents groupes du Paléolithique supérieur, la plupart orientés vers l'Est avec continuation jusqu'au Pléistocène tardif ou au Postpléistocène et à la transition vers le Mésolithique, sans nette discordance entre Paléolithique supérieur et Mésolithique.

La corrélation avec le système stratigraphique du Pléistocène de l'Allemagne du Sud n'est possible qu'avec des réserves et en utilisant quelques notions terminologiques auxiliaires: La première présence de l'homme est fixée dans une période chaude de longue durée, qui est limitée vers la bas par la période froide du "Do n a u ", vers le haut par la période froide "N" (abréviation auxiliaire par l'auteur). Elle comprend les "Deckenschotter" comme oscillations froides " $G$ " et " $M$ ". La deuxième présence de l'homme doit-être attribuée à la fin de l'interglaciaire de Steinhei m. La troisième, la quatrième et la cinquième présence de l'homme sont en relation avec la période glaciaire " $R$ " et avec l'interglacia ire de Stutgart qui s'y joint. Le reste du Paléolithique inférieur et le Paléolithique supérieur tout entier appartiennent au Wü $\mathrm{rm}$, le Mésolithique à l'Holo cè n e inférieur.

Abstract: The Palaeolithic inventories of Southern Germany may be divided stratigraphically as follows:

First Early Palaeolithic presence of man in the end of a long lasting Lower Pleistocene warm period, probably just before the "Oldest Loess" of Southern Germany. Pebbletools of Mauer near Heidelberg.

Second presence of $\mathrm{man}$ in the last stage of the next-following interglacial phase. Ancient flake-instruments of Old Palaeolithic form.

$\mathrm{Th}$ ird prese $\mathrm{nce}$ of $\mathrm{m}$ a $\mathrm{n}$ in an interstadial of the following cold-stage. Slightly evolved flake-artifacts connected with a small hand-axe-component.

Fourth prese $\mathrm{nce}$ of $\mathrm{man}$ just before or in the beginning of the last interglacial stage. Traces of hand-axe-scrapers (Abb. 2).

$\mathrm{Fifth}$ presence of $\mathrm{man}$ in the upper part of the same stage. Mousteroid artifacts and beginning of "Blattspitzen"-tendencies.

Sixth Old Palaeolithic stage (continuation of the fifth) in the transitional stage of the lower part of the last cold-stage. Unspecialised inventories of upper Old Palaeolithic age, Old Palaeolithic connected with "Blattspitzen" (leaf-shaped points), Old Palaeolithic groups connected with increased grattoirpercentage, "Haldenstein-blade" as upper limit of Old Palaeolithic groups.

First Younger Palaeolithic presence of man in or may be shortly before Main-Oszillation of the last cold-stage ("Main-Oszillation" by reason of the possibility of an older - outside of Southern Germany observed - interstadial and at least two younger ones belonging to the same last cold-phase). Lower Younger Palaeolithic implements resembling western Aurignacien I and corresponding inventories of the East.

L a sting presence of $\mathrm{m}$ a $\mathrm{n}$ in Upper Würm by different, mostly eastwards orientated Younger Palaeolithic groups up to the Late- and Postglacial, without sharp limitation between Younger Palaeolithic and Mesolithic industries.

The correlation with the general stratigraphical system of the Southern German Pleistocene can be done provisionally only and by use of auxiliary terms: The first presence of man stands in the end of a long lasting warm stage, which is limited by the D o n a u glacial and the "N"cold - stage (provisional term by the author) and is including the " $\mathrm{Deckenschot}$ e $\mathrm{r}$ " as " $G^{\text {" }}$ - a nd "M"-cold-oscillations with unknown climatic importance and endurance. The second presence of man is to put into the end of the $\mathrm{Ste}$ inheim interglacial, whereas the third, fourth and fifth are connected with the following " $R$ "-cold-s t a ge and the "Stuttgartinterglacial". The rest of the Old and all the Younger Palaeolithic industries are to put into $\mathbb{W} \ddot{\mathrm{u}} \mathrm{rm}$, the Mesolithic into the Lower Holocene. 
Die ersten paläolithischen Funde im engeren süddeutschen Becken liegen noch keine hundert Jahre zurück. Seit den frühen, mehr zufälligen Anfängen (Schussenquelle 1865/ 66, O. FraAs 1866) hat sich die Zahl der bekannten und in neuerer Zeit auch oft sorgfältig ergrabenen altsteinzeitlichen Fundstellen auf mehr als 150 erhöht. Unter ihnen befinden sich nicht wenige Stationen mit mehreren, zeitlich voneinander getrennten Begehungshorizonten. Trotz der Vielzahl der noch immer klaffenden Lücken ergibt sich doch bereits eine archäologisch belegbare Zeitspanne von recht erheblichen Ausmaßen. Dazu kommt die relative Erleichterung der stratigraphischen Gliederung der vorhandenen kulturellen Belege, die durch die Vielgestaltigkeit und unterschiedliche Klimaabhängigkeit der einbettenden Sedimente in Süddeutschland bedingt wird. Seit den grundlegenden Untersuchungen A. PENCK's \& E. BRüCKNER's (1901/09) im alpinen Raum gehört Süddeutschland zu den Ausgangsbereichen der klassischen Quartärforschung überhaupt, dessen Westgebiete vor allem in nicht unerheblichem Maße an der Entwicklung ihres Systems beteiligt gewesen sind. Gerade dadurch ist dieses Gebiet trotz einer Unzahl von Modifikationsversuchen und echten Modifikationen für die allgemeinen Kenntnisse des Pleistozäns auch heute noch von beträchtlichem Interesse. Vor allem die Verknüpfung periglazialer und glazialer Erscheinungen auf relativ engem Gebiet verstärkt seine Bedeutung. Zumal in einem Augenblick, in dem eine ganze Reihe von grundsätzlichen Problemen, die mehr oder weniger in den Schwierigkeiten der Verbindung glazialer und periglazialer Folgen ihre Ursache $\mathrm{zu}$ haben scheinen, der zukünftigen Lösungen harren. Es sollte aber nicht unbeachtet bleiben, daß schon die frühesten Arbeiten A. Penck's Beziehungen zwischen Periglazial und Glazial herstellen, die auch jetzt noch nicht ohne weiteres alle auf die Seite zu schieben sind. Wie anderswo, so liegt gegenwärtig auch in Süddeutschland das Schwergewicht auf der Erforschung des Periglazials. Vor allem die Lößgliederung hat hier deutliche und eindrückliche Fortschritte zu verzeichnen (H. Freising 1949, 1951; F. Weidenbach 1952; K. Brunnacker 1953, 1956b; J. FINK 1956). Die Arbeiten im glazialen Gebiet sind daneben zunächst erheblich ins Hintertreffen geraten. Trotzdem erfolgt noch immer häufig genug eine vorschnelle Verbindung periglazialer Ergebnisse mit oft lange zurïckliegenden Geländebeobachtungen und sich daraus ergebender Folgerungen im Bereich der alpinen Gletscher, die für viele Feinheiten keineswegs mehr als zuverlässig genug und ausreichend zu betrachten sein dürften. So darf wohl, um ein konkretes Beispiel zu nennen, ohne jede Einschränkung behauptet werden, daß etwa die Hauptschwankung des Würm, die im periglazialen Löß einwandfrei erscheint, in den glazialen Moränefeldern zumindest der westlichen Alpen bisher keineswegs unangreifbar erkannt und vorgelegt worden ist. Dieser Rückstand der Glazialgliederung im engeren Sinne dürfte wohl nur durch eine großzügige Neuaufnahme des gesamten alpinen Gebietes im Sinne A. Penck's und E. BRÜCKNER's wieder einzuholen sein. Eine Aufgabe, deren Lösung auch der Gliederung des süddeutschen Periglazials und darüber hinaus der pleistozänen Stratigraphie im weitesten Sinne wesentliche Neuerkenntnisse vermitteln könnte. Bei der vorläufig gegebenen Lage bleibt dem Paläolithiker, der seine Materialien ja irgendwie möglichst zuverlässig einstufen soll, nichts anderes übrig, als sein Augenmerk hauptsächlich auf die Räume außerhalb der Gletscherzone zu lenken. Hat er es doch in erster Linie, oder beinahe ausschließlich, mit Funden aus dem Periglazial (wenn nicht überhaupt gar aus interglazialen Warmphasen) zu tun. Dies muß auch auf die Gefahr hin geschehen, daß dadurch eine vorübergehende Suspendierung eines Teiles der im glazialen Bereich geformten Terminologie hervorgerufen werden könnte, ohne daß aber, was die ganze Problematik eines derartigen Vorgehens verdeutlicht, mehr als sehr allgemeine archäologisch gebundene Begriffe als zeitweiliger Ersatz zur Verfügung stehen. Auf jeden Fall sollte nicht gerade die Rücksicht auf den Prähistoriker (wie R. Grahmann sie einmal in der Diskussion in Aarau 1954 forderte) eine Beibehaltung der eingeführten geologischen Terminologie, wo sie nur noch mühsam gehalten werden kann, begründen und fördern. 
Denn gerade die Paläolithforschung hat, auch wenn dies mit einer sehr wandlungsfreundlichen Terminologie geologischer Begriffe bezahlt werden müßte, ein außerordentliches Interesse an einer endgültigen, wenn zunächst auch groben Gliederung des Pleistozäns. Erst danach kann sie sich ihren eigentlichen kulturhistorischen Aufgaben zuwenden.

Bei der folgenden Betrachtung der süddeutschen Paläolithika, der diese zwar allgemeinen, aber doch notwendigen Bemerkungen vorauszuschicken waren, ist es seibstverständlich unmöglich, alle vorhandenen Stationen im einzelnen zu behandeln. Für die hier angestrebte Übersicht ist dies auch keineswegs notwendig, sondern es genügt vielmehr eine Beschränkung auf einige wenige, aber stratigraphisch aussagekräftige Aufschlüsse. Einige zeitliche und regionale Komplexe des süddeutschen Paläolithikums liegen bereits bearbeitet vor (G. RieK 1935; O. Roller 1953; Hj. Müller-Beck 1956). Außerdem befinden sich in einer Anzahl von Sammelarbeiten über größere Gebiete zahlreiche Hinweise auf das Fundmaterial unseres Gebietes und aus ihm gewonnene Folgerungen (R. R. Schmidt 1912; H. Obermaier 1912; F. Wiegers 1928; J. Andree 1939; L. F. Zotz 1951; G. Freund 1952; K. J. NARR 1955), ohne auf wesentliche, hierher gehörige Zeitschriftenaufsätze eingehen zu wollen. Ebenso kann auf die Einzelpublikationen nur summarisch verwiesen werden. Sie sind weitgehend vor allem bei R. R. Schmidt (1912) und J. Andree (1939) aufgeführt.

Die ältesten in diesem Rahmen zu behandelnden Funde aus Süddeutschland sind diejenigen von $\mathrm{M}$ a u e $\mathrm{r}$ unweit Heidelberg. Außer dem von dort stammenden Unterkiefer des Homo heidelbergensis (O. SCHOEtEnsack 1908) sind seit den Entdeckungen von A. Rust (1956a, 1956b) in den letzten Jahren auch die zugehörigen Artefakte bekannt. Daß über den Werkzeugcharakter dieser Stücke diskutiert wird, ist durchaus begreiflich, gehört doch zum Erkennen derartiger oft ganz neuer Formen eine außerordentliche typologische Erfahrung und vor allem auch eine Einarbeitung in die sich stellenden besonderen Probleme, die nicht ohne weiteres zu erlangen oder zu ersetzen sind. Auf jeden Fall liegen unter den aus Mauer vorgelegten Exemplaren Formen vor, die nach jeglicher gültigen archäologischen Erfahrung nicht anders als als Werkzeuge zu betrachten sind. Wenn hier auch nicht der Platz einer eingehenden Diskussion dieser Frage gegeben ist, so sei doch darauf verwiesen, daß das den Artefakten von Mauer recht ähnliche Kafuan Afrikas (L. S. B. LeAKey 1953; C. van RiEt Lowe 1952) zwar in einzelnen Punkten ebenfalls noch umstritten ist, aber gerade jene Faktoren, die es mit Mauer verbinden, mit völliger Selbstverständlichkeit als älteste afrikanische Kulturrelikte angesehen werden.

Die stratigraphische Stellung von Mauer ist immer wieder diskutiert worden. Aus der Vielzahl der dazu vorliegenden Arbeiten seien hier nur diejenigen von E. KoKeN (1912) als Zusammenfassung der älteren Beobachtungen, W. SoergeL (1933), E. BEcKsMANN (1950) und S. Kuss (1955) herausgegriffen. Das vereinfachte, während der letzten Jahre aufgeschlossene Profil der Grube Grafenrain zeigt folgenden Aufbau (Abb. 1): Im Liegenden in ältere, stark verwitterte Schotter eingeschachtelte Neckarschotter, die in verschiedenkörnige, von Ton- und Lehmbändern durchzogene Sande übergehen, deren unterster Abschnitt die menschlichen Spuren ergab (A. Rust 1956a). Der obere Abschluß der Sande ließ gelegentlich eine klare, bisweilen aber stark verschleierte Diskordanz erkennen, wie sie bereits E. KoKen (1912) beschrieb. Eine neue Beobachtung (die erst im Dezember 1956 durch den Verfasser gemacht werden konnte), hilft hier offenbar etwas weiter: Diskordant zu den Sanden im Liegenden, mit ihnen aber deutlich verwürgt, erschien ein $15 \mathrm{~m}$ langer und bis $1 \mathrm{~m}$ mächtiger Streifen verlehmten, rötlichen Sandes, der sich sowohl in der Lagerung wie auch in der Beschaffenheit eindeutig von den in die Sande eingeschalteten graubraunen Lehmlinsen und Lehmhorizonten unterschied. Der darüber folgende, teilweise erheblich entkalkte Löß ist mehr oder weniger stark ver- 


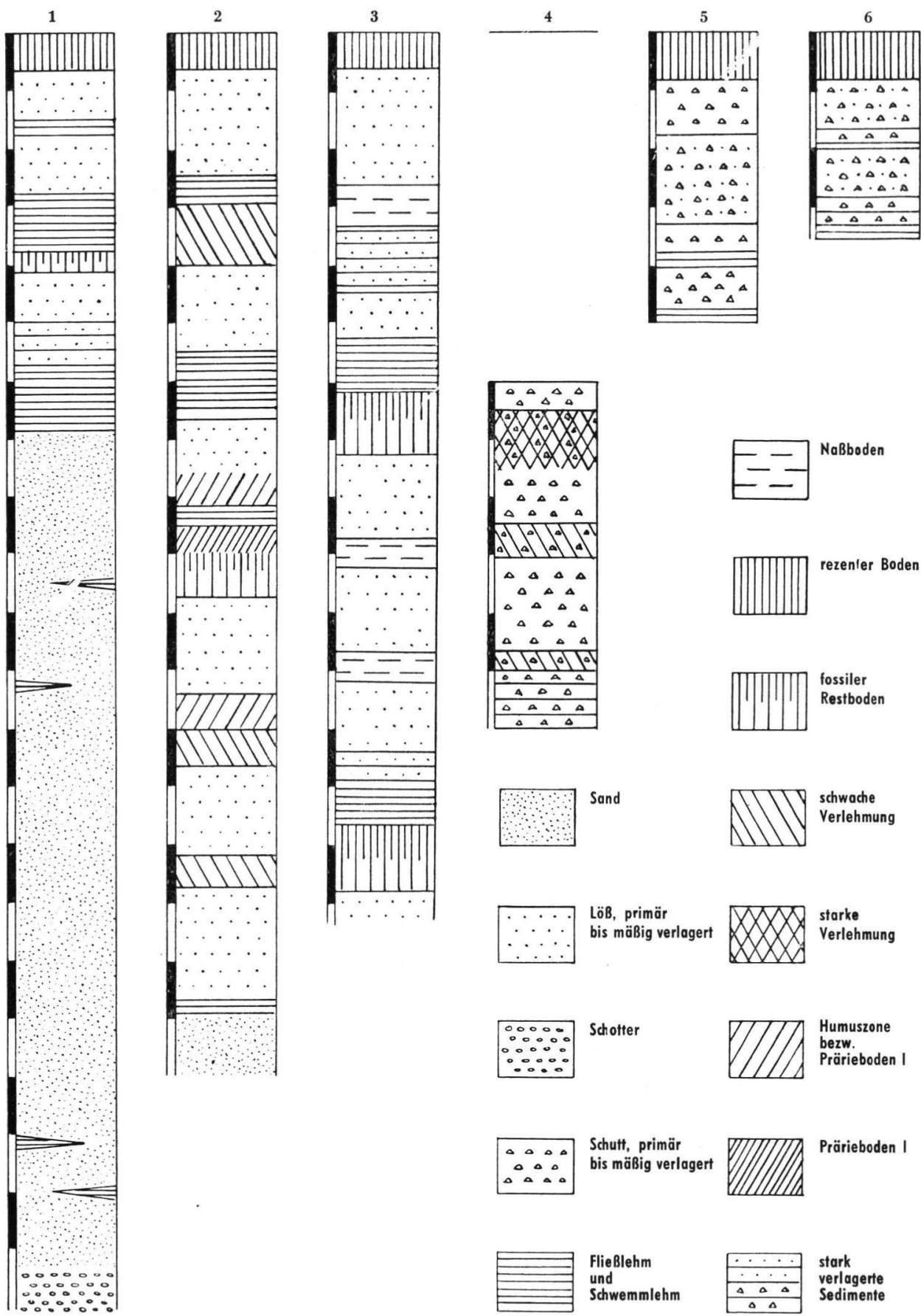

Abb. 1. Pleistozäne Sedimentabfolgen: 1. Mauer, Grafenrain, südliche Westwand im Dezember 1956; 2. Sammelprofil der nordwestfranzösischen Lößaufschlüsse; 3. Böckingen, Ziegelwerke (J. FinK 1956), Ergänzungen der beiden unteren Naßböden nach Beobachtungen im Herbst 1954; 4. La Micoque, Südwestfrankreich, leicht schematisiert, im Herbst 1955; 5. Stetten/Lonetal, Vogelherd, vereinfachtes Sammelprofil (G. RIEK 1934); 6. Mauern, Weinberghöhlen, vereinfachtes Sammelprofil (A. BoHmers 1951). 
lagert und an seiner Unterkante mit dem verlehmten rötlichen Sand im Liegenden verwürgt. Über diesem unteren Löß folgen verflossene Bodenreste, die stellenweise doch eindeutig in ihrem waldbodenartigen Charakter zu erkennen sind. Ein oberer, bisweilen durch eine kleinere Fließerde zweigeteilter Löß bildet unter Einbeziehung der rezenten Verlehmung den Abschluß (A. Rust 1956a).

Die Schotter und Sande sind sicher warmzeitlich abgelagert, haben aber kaum, wie so oft bei gletscherunabhängigen Flüssen, klare klimatische Beziehungen, sondern verdanken ihre Entstehung im wesentlichen tektonischen Vorgängen (E. BEcKsmanN 1939, 1950). Die warmzeitliche Bildung der Sande ist durch die eingeschlossene Fauna gesichert, wenn auch ihr oberer Abschnitt offenbar eine Klimaverschlechterung erkennen läßt (bereits E. KoKen 1912 - neuere Beobachtungen dazu an anderer Stelle). Die zu den Sanden diskordante Zone des verlehmten rötlichen Sandes besitzt auffallende stratigraphische Gemeinsamkeit mit den roten Sanden Commont's im Liegenden der Lößfolge des Seinebeckens (F. Bordes 1954; F. Bordes - Hj. Müller-Beck 1956). In Mauer stellt sie offenbar den Rest einer sehr wahrscheinlich warmzeitlichen, anschließend umgelagerten Verwitterung dar. Es wäre durchaus denkbar, daß das Gebiet der Mauerer Neckarschlinge in einer Kaltzeit, in die die Ablagerung der oberen Sande noch hineinreicht, Erosions-, aber noch nicht Akkumulationsraum äolischer Vorgänge gewesen ist. Eine Tatsache, die vor allem durch das Fehlen des erst noch zu bildenden Geländereliefs in dem ebenen, vom Neckar verlassenen, relativ breiten Talboden recht gut zu erklären wäre. Die beiden Lößabfolgen im Hangenden stellen zwei weitere, durch die interglaziale Bodenbildung getrennte Kaltphasen dar. Demnach wäre das Profil von MauerGrafenrain vielleicht doch vollständiger, als dies bisher im allgemeinen den Anschein hatte. Wenn auch wegen der anhaltenden kleinräumigen Zertalung nach wie vor mit stratigraphischen Lücken gerechnet werden muß, so besteht doch immerhin die Möglichkeit, daß alle auf die Ablagerung der fossilführenden Sande folgenden Klimaabschnitte wenigstens in groben Zügen direkt oder indirekt belegt wären. Auf das Liegende der Fundschichten soll an dieser Stelle wegen des Umfanges der daran zu knüpfenden Erörterungen nicht eingegangen werden. Doch auch die dort zu beobachtenden Verhältnisse scheinen die Stellung des Homo beidelbergensis und seiner Artefakte am Ausgang einer Warmzeit von recht erheblicher Länge zu bestätigen. Die Artefakte selbst sind durch ihre eher einfache Gestalt und allgemein grobe Ausführung gekennzeichnet. Wieweit eine Gleichzeitigkeit mit ähnlich oder verschieden gearteten Geräteinventaren anderer geogtaphischer Räume vorliegt, ist vorläufig nicht $\mathrm{zu}$ entscheiden. Ebenso unklar ist noch, wie tief der in Mauer belegte Industriekomplex (Heidelberger Kultur, A. Rust 1956a) zeitlich zurückreicht.

Ein zweites, jüngeres, von Mauer faunistisch klar getrenntes Interglazial (K. D. AdAM 1952, 1953a, 1954) wird durch den Schädel von Steinheim (F. BERCKHEMER 1933) und die zugehörige Fauna belegt. Aus dem eigentlichen Interglazial, das von nicht unerheblicher Länge gewesen sein dürfte, liegen aus Süddeutschland bisher keine gesicherten Artefakte vor. Dagegen sind wiederum Funde aus dem Ende dieser Warmzeit, beziehungsweise dem Übergang zur folgenden Kaltphase bekannt. Einmal erscheinen hierher gehörige paläolithische Spuren im Löß von Böckingen (Hj. MüLleR-BECK 1956) und zum anderen in zwei Höhlenstationen der Schwäbischen Alb. In Böckingen liegen einige wenige Artefakte einer eher groben Abschlagkultur (Hj. MüLLER-BECK 1956) unmittelbar über den Resten eines auf dem ältesten Löß Süddeutschlands (Freising's Löß I) entstandenen Waldbodens (Abb. 1). Uber den aus diesem unteren Waldboden hervorgegangenen Fließerden folgt ein in der Grube zwar unterschiedlich gegliederter, aber generell wohl dreigeteilter Löß, der von einer weiteren intensiven Bodenbildung und dem jüngsten, durch einen Naßhorizont zweigeteilten Löß (FrEIsING's Löß III) überlagert wird (H. Freising 1953; J. Fink 1956). Ebenso eindeutig sind die Verhältnisse 
der noch nicht publizierten, aber in verschiedenen Vorträgen des Ausgräbers R. WETzEL erwähnten ältesten Kultur der Bockste in schmiede. Sie liegt an der Basis einer kaltzeitlichen Schuttfolge, deren Oberkante ganz offensichtlich eine teilweise in situ erhaltene warmzeitliche Verwitterung aufweist (H. Freising 1954; R. WETzEL 1954; Hj. MülLER-BECK 1956). Über diesem unteren Kaltschutt folgt eine weitere kaltzeitliche Schuttfolge (R. Wetzel 1954), die der letzten Kaltzeit angehören dürfte. Ähnlich, wenn auch weniger vollständig, scheint die stratigraphische Gliederung des Vogelherdes (Abb. 1) zu sein. Über der Kultur der Höhlensohle (G. RIEK 1934) liegt eine untere, von einem verlagerten Verwitterungslehm ïberdeckte Schuttbildung (H. FreISING 1954) sowie ein zweiter ausbildungsmäßig deutlich unterschiedener Schuttzyklus, der end-altpaläolithische (RIEK VI) und jungpaläolithische (RIEK V und höhere) Inventare enthält. Die aus einfachen Abschlaggeräten bestehende Kultur der Höhlensohle im Vogelherd (RIEK IX) wird von einem Auswurfzahn eines jugendlichen Elephas antiquus begleitet (G. Riek 1934; U. Lehmann (n. K. D. Adam 1954).

Aus den eigentlichen Kältephasen der auf das Steinheimer Interglazial folgenden vorletzten Kaltzeit sind in Süddeutschland bisher keine paläolithischen Funde bekannt. Erst aus dem Ausgang dieser Zeit liegen, offenbar im Bereich einer kürzeren, aber recht ausgeprägten interstadialen Warmschwankung, wiederum altpaläolithische Steingeräte vor. Es handelt sich um das relativ einfache Inventar von $\mathrm{M} \mathrm{u} \mathrm{r} \mathrm{g}$, das im wesentlichen, neben einem einzigen atypischen Faustkeil, nur Abschlagtypen besitzt (G. KRAFT 1936; Hj. MüLler-Beck 1956). Die etwas vereinfachte Schichtfolge der Fundstelle zeigt folgende Entwicklung: Über der verschleppten Grundmoräne der größten alpinen Vergletscherung folgt eine sandige Zone, die die Artefakte birgt, darüber zunächst verlagerter unreiner und dann reiner Löß, über den sich eine stark verflossene und deshalb nur relativ selten eindeutig erkennbare interglaziale Bodenbildung legt. Den Abschluß bildet ein durch eine Zone stärkerer Bewegung zweigeteilter oberer Löß (F. Z Z INK 1940; E. SChMid 1951; Hj. MüLler-Beck 1956).

Noch jünger als die eben erwähnten Funde von Murg sind mit Sicherheit die paläolithischen Hinterlassenschaften aus der Hauptfundschicht der B ocks te in s ch mie de (R. Wetzel 1940, 1954) mit den für sie typischen Faustkeilschabern (Abb. 2) (Hj. MüLLER-BECK 1956). Sie gehören ebenfalls noch der vorletzten Kaltzeit an und liegen unmittelbar unter den Verwitterungsbildungen der letzten fossilen Warmzeit. Ein Teil der Artefakte weist sogar Einflüsse dieser Verwitterungsvorgänge auf. Gleichzeitig mit diesem Fundhorizont sind auf Grund der stratigraphischen wie auch der artefakttypologischen Verhältnisse die Funde aus der Strate VIII des Vogelherdes (Abb. 2) (G. RIEK 1934; H. Freising 1954, Hj. MüLler-Beck 1956). Das durch einen Faustkeilschaber gekennzeichnete Inventar war ebenfalls in einem älteren, von allerdings nicht in situ befindlichen Verlagerungsprodukten und einer zweiten andersgearteten Kaltschuttbildung überlagerten Schutthorizont eingebettet.

Ein Vergleich zwischen den aus der vorletzten Kaltzeit stammenden Inventaren Süddeutschlands und annähernd gleichzeitigen anderer Räume läßt sich bisher nur sehr allgemein durchführen. Die Abschlagtypen erinnern an das französische Moustérien, zeigen aber häufig eine levalloisartige Technik und daneben durchaus eigenständige Züge. Kennzeichnend ist die annähernd vollständige Faustkeillosigkeit der aus dem Beginn der vorletzten Kaltzeit und dem Interstadial von Murg vorliegenden Gerätekomplexe. Die durch die Arbeiten von F. Bordes (1954) gut datierten, etwa phasengleichen reicheren paläolithischen Hinterlassenschaften aus dem zweifellos klimagünstigeren nordfranzösischen Seinebecken (Abb. 1) weisen im Gegensatz dazu ganz erhebliche Faustkeilanteile auf. Ahnlichere Funde liegen dagegen aus den unteren und mittleren Straten von $\mathrm{L}$ a $\mathrm{M}$ ic o q u e vor, die bisher sehr summarisch dem "Tayacien“ zugeteilt worden sind (H. BreuIL 1932 a, b). Die dortige, recht aufschlußreich gegliederte Schutt- 


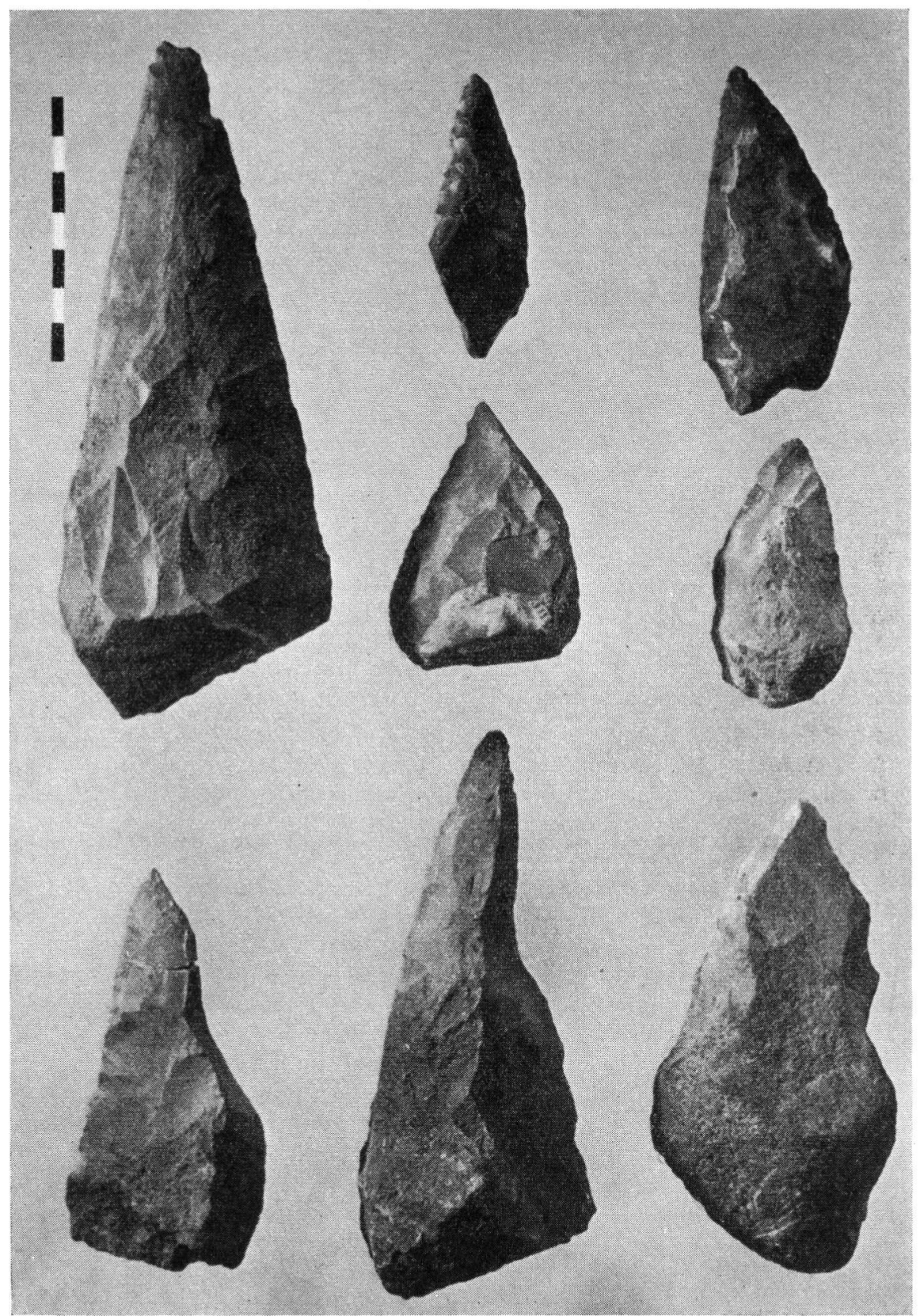

Abb. 2. Faustkeilschaberinventare, Typenauswahl: Essing, Klausennische (obere drei Exemplare), typologisch fortschrittlich, stratigraphisch nicht eindeutig, vielleicht erst Übergang zu W'ürm; Stetten/Lonetal, Vogelherd, Schicht VIII (mittlere zwei Exemplare), Ausgang R-Kaltzeit - Beginn Stuttgarter Interglazial; Rammingen, Bocksteinschmiede, Hauptfundschicht (untere drei Exemplare), Ausgang R-Kaltzeit - Beginn Stuttgarter Interglazial. (Foto H. Hell, Tübingen). 
folge (Abb. 1) dürfte - mit Ausnahme des obersten Abschnittes - mit ziemlicher Wahrscheinlichkeit der vorletzten Kaltzeit angehören und damit stratigraphisch dem unteren Schuttkomplex der Bocksteinschmiede entsprechen. $\mathrm{Zu}$ beachten ist hierbei aber, daß die paläolithischen Funde nicht nur auf den klimagünstigen Abschnitt des Kaltzeitbeginns und die interstadialen Schwankungen, wie in Nordfrankreich oder Süddeutschland, beschränkt sind, sondern daß die Verteilung der Artefakte über das gesamte Profil von La Micoque eine anhaltende, praktisch wohl die ganze vorletzte Kaltzeit einnehmende paläolithische Begehung Südfrankreichs wahrscheinlich macht. Gewisse Beziehungen des faustkeilfreien Altpaläolithikums der vorletzten Kaltzeit scheinen außerdem zu den älteren, faustkeilarmen Gruppen Mitteldeutschlands zu bestehen, von denen hier nur die Stationen von Markkleeberg (R. GrahmanN 1955) erwähnt seien.

Die Faustkeilschaberinventare Süddeutschlands besitzen mit dem französischen Micoquien einen nur sehr indirekten, lockeren Zusammenhang. Der typische Faustkeilschaber (R. WetzeL: Bocksteinmesser) (Abb. 2) fehlt westlich des Rheines nahezu ganz, tritt aber östlich davon, bis zur Ostgrenze acheuloider Komplexe überhaupt, unter verschiedener stratigraphischer Horizontierung nicht gerade selten auf. Eine etwas nähere Beziehung scheint dagegen zum späten Freiland-Acheuléen Nordfrankreichs (F. Bordes 1954), das auch mit dem anschließenden Micoquien im engeren Sinne nicht direkt gleichgesetzt werden darf, zu bestehen. In diesen nordfranzösischen Industrien kommen relativ häufig am Basisende rückenartig abgeschrägte Faustkeile vor, die aber nicht ganz den echten Faustkeilschabern mit keilförmigem, dreieckigem Querschnitt und ausgeprägtem Rücken entsprechen. Das mag seinen Grund darin haben, daß zwischen den dem jüngsten Acheuléen angehörenden Faustkeilen Nordfrankreichs und den Faustkeilschabern Süddeutschlands eine nicht unbeträchtliche Zeitdifferenz besteht. Das Jungacheuléen Nordfrankreichs ist in die letzte größere Oszillation der vorletzten Kaltzeit zu stellen (F. Bordes 1954), die Faustkeilschaber dagegen in das beginnende "Postglazial" der gleichen Periode. Das bedeutet aber, daß zwischen beiden Fundhorizonten ein Abstand von mehreren Jahrtausenden liegenden muß, der etwa größenordnungsmäßig dem Zeitraum zwischen mittlerem Jungpaläolithikum und mittlerem Mesolithikum Mitteleuropas entsprechen dürfte. Die Zeitstellung der osteuropäischen Faustkeilschaberkomplexe, die zumindest zu einem Teil jünger als die hier behandelten sein dürften, ist vorläufig noch unklar.

Aus dem letzten Interglazial sind nur sehr wenige süddeutsche Funde bekannt. Allein die Artefakte aus den Travertinen von Stuttgart-Untertürkheim (F. BERCKHEMER 1935a; Hj. MüLLER-BEcK 1956) können mit Sicherheit in diesen Klimaabschnitt gestellt werden. Die begleitende Fauna ist eindeutig warm und unterscheidet sich klar von der des vorangehenden Interglazials von Steinheim (F. BErcknemer 1935b; K. D. AdAm 1953b). Die bisher publizierten und zugänglichen paläolithischen Funde besitzen wiederum einen allgemeinen mousteroiden Charakter, dem sich aber eine leichte Blattspitzentendenz als Sonderzug zugesellt. Der obere, sandige Abschnitt der fundführenden Travertine läßt bereits eine gewisse Klimaverschlechterung erkennen, die durch die eingeschlossenen Faunen- und Florenreste deutlich zum Ausdruck kommt (F. BERcкhEmer 1935a, b). Direkte Entsprechungen des Paläolithikums aus dem Stuttgarter Interglazial sind bisher nicht bekannt. Gewisse allgemeinere Verbindungen scheinen einerseits aber mit dem Inventar von Weimar-Ehringsdorf (J. ANDREE 1939) und andererseits mit den etwas jüngeren altpaläolithischen Blattspitzengruppen Süddeutschlands (Hj. MüLLERBECK 1956) zu bestehen. Sicher in das Stuttgarter Interglazial zu datierende Menschenreste liegen aus Süddeutschland bisher nicht vor.

Sehr viel zahlreicher dagegen sind die kulturellen Hinterlassenschaften aus dem Übergang zur letzten Kaltzeit. Eine ganze Reihe von süddeutschen Höhlen- und Lößstationen haben hier einzureihende Funde erbracht (Hj. MüLleR-BECK 1956). Neben 


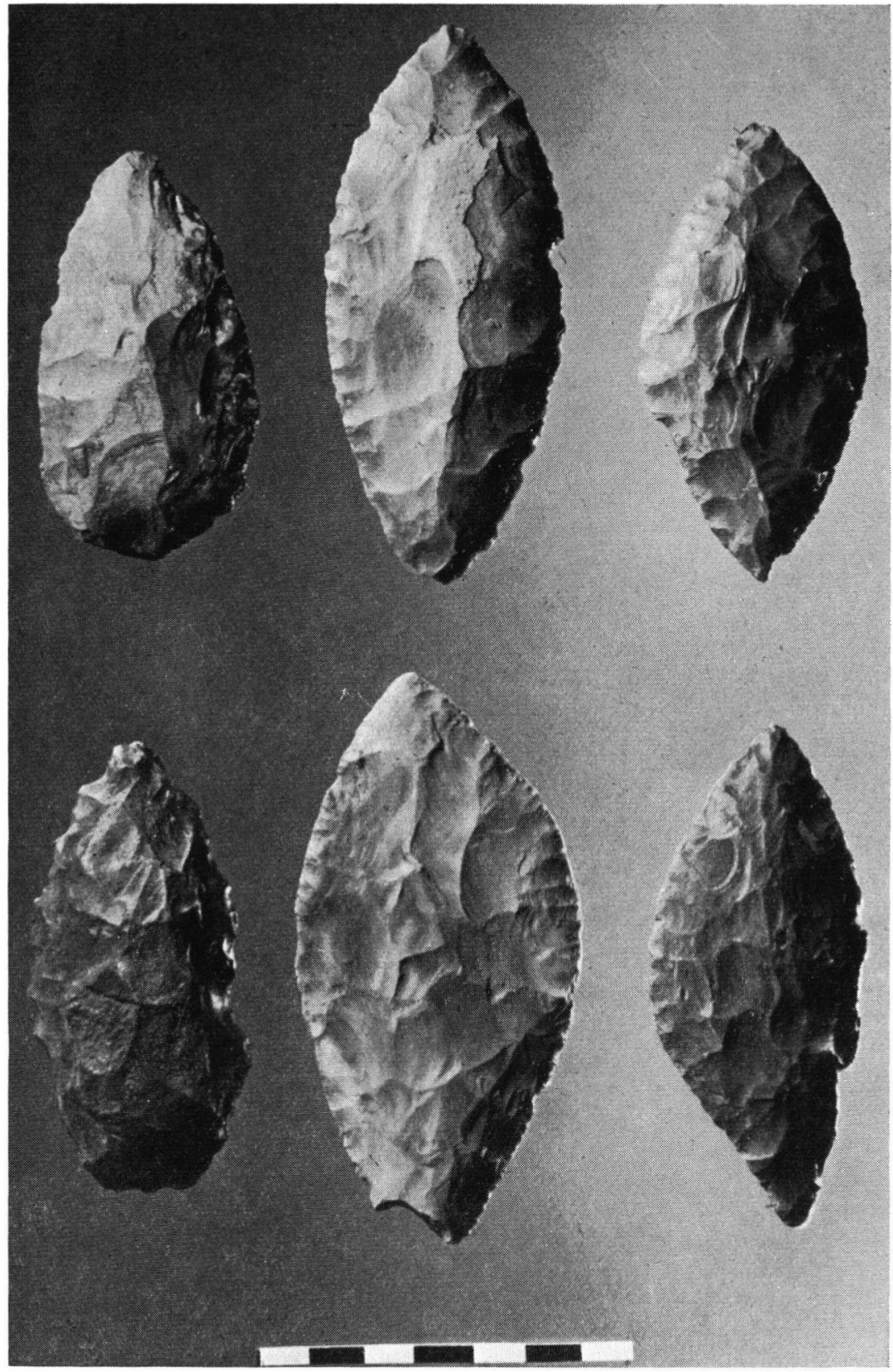

Abb. 3. Blattspitzen aus dem Unteren Würm Süddeutschlands: Holheim, Kleine Ofnet (linke Reihe); Mauern, Weinberghöhlen (mittlere Reihe); Urspring, Haldensteinhöhle (rechte Reihe). (Foto H. Hell, Tübingen).

allgemein-mousteroiden Inventaren verschiedenster Tendenz ist besonders die Gruppe des Altpaläolithikums mit Blattspitzen (H. ObermaIer \& P. Wernert 1929; G. Freund 1952) hervorzuheben (Abb.3). Sie erscheint bereits in der wahrscheinlich relativ früh 
innerhalb des Überganges zu datierenden Freilandstation von Kösten bei Lichtenfels (H. Obermaier \& P. Wernert 1929; Hj. Müllen-Beck 1956) und gehört in verschiedener Ausbildung, wie etwa in Mauern (L. F. Zotz 1955), zu den vor allem im östlichen Süddeutschland relativ häufigen Inventaren dieser Periode (G. FREUND 1952; Hj. MüLler-BECK 1956). Der wahrscheinlich jüngste in diesen Zusammenhang gehörige Blattspitzenkomplex der Haldensteinhöhle (G. RIEK 1938) fällt bereits in den Bereich der weiträumigen Lößsedimentation in Süddeutschland. Die hier gemachten Funde werden durch zwei ausgezeichnet gearbeitete und typologisch entwickelte Blattspitzen (Abb. 3) gekennzeichnet, sowie durch eine große, schwere Klinge, die auch in anderem Zusammenhang auftritt, aber wegen der in diesem Komplex so außerordentlich typischen Ausprägung geradezu als $\mathrm{Haldenstein-Klinge} \mathrm{bezeichnet} \mathrm{werden} \mathrm{darf.}$

Neben den eben behandelten Blattspitzeninventaren läßt sich eine weitere, etwas schärfer zu umreißende Industrie des späten süddeutschen Altpaläolithikums ausscheiden. Es handelt sich um im Gesamthabitus altpaläolithische Inventare, die neben den üblichen Schaber- und Spitzenformen beträchtliche Kratzeranteile führen. Diese hohen Kratzeranteile geben oft die Veranlassung, derartige Komplexe als Aurignacien (etwa K. Gumpert 1952, 1953) zu bezeichnen. Dazu ist zu sagen, daß auch im ausgehenden Altpaläolithikum westlich des Rheines bereits häufig ganz erhebliche Kratzerbeimengungen auftreten (F. Bordes, Typus 30 und 31), die große Prozentsätze und gute typologische Ausprägung erreichen können. Die restlichen Geräte zeigen dabei ebenfalls das normale altpaläolithische Gepräge. Es geht in Süddeutschland auf keinen Fall an, derartige Inventare, wenn man die Vergleichsbasis mit dem Westen nicht völlig auflösen will, als Jungpalöolithikum zu beschreiben. Dies wäre außerdem auch nur unter gleichzeitiger grundsätzlicher Änderung der französischen Terminologie und ihrer Grundlagen möglich.

Es sei in diesem Zusammenhang darauf hingewiesen, daß sehr viele Interpretationsdifferenzen im Bereich des Überganges vom Alt- zum Jungpaläolithikum offenbar auf diesen Bestimmungsfehler zurückgehen, der leider häufiger in Erscheinung tritt, als man auf den ersten Eindruck hin meinen sollte. Es hat sogar den Anschein, als ob dieser Auffassungsunterschied auch recht beträchtlich an einigen Gegensätzen der stratigraphischen Gliederung des Oberen Pleistozäns in West- und Osteuropa beteiligt ist. Man sollte prinzipiell an der klaren Typologisierung des Jungpaläolithikums festhalten, wie sie durch das Aurignacien I H. Breuil's (1912) und die unteren Stufen des Périgordien D. Peyrony's $(1936,1948)$ gegeben ist. Wobei allerdings zu bemerken bleibt, daß das Périgordien I noch keine scharfe Trennungslinie darstellt, sondern starke altpaläolithische Züge besitzt, die erst mit der folgenden Stufe zurücktreten. Daß der eigentlichen Zäsur zwischen Alt- und Jungpaläolithikum eine Ubergangsphase verschiedener Ausbildung und vor allem je nach Art der zusammenstoßenden Komponenten auch verschiedener Ursache vorausgehen kann, bleibt selbstverständlich. Trotzdem sollte man zur Vereinfachung der Verständigung besser alle eventuellen oder wirklichen Übergangsindustrien nicht aus dem Altpaläolithikum herauslösen und das Jungpaläolithikum erst mit dem Aurignacien I H. BREuIL's oder typologisch gleichwertigen Gruppen (wie etwa dem Prä-Aurignacien A. Rust's (1950) im syrischen Jabrud) beginnen lassen. Unter diesem Gesichtswinkel wäre der eher verwirrende Begriff des „Mittelpaläolithikums“ besser wieder zu streichen, da eine echte Diskordanz zwischen ihm und dem Altpaläolithikum - wie sich immer deutlicher zeigt - gar nicht besteht. So wäre auch das Périgordien I eher noch dem Altpaläolithikum einzuordnen, was beim Typenbestand der jüngeren Périgordienstufen nicht mehr zulässig sein würde. Unklar wird die Grenzlinie zwischen Jung- und Altpalöolithikum anscheinend auch dadurch, daß östlich des Rheines ausgearbeitete Knochengeräte bereits im Zusammenhang mit altpaläolithischen Inventaren (A. Tode 1953; G. RIEK 1934 - Vogelherd VI; vgl. Abb. 4) auftreten, wie wir sie west- 


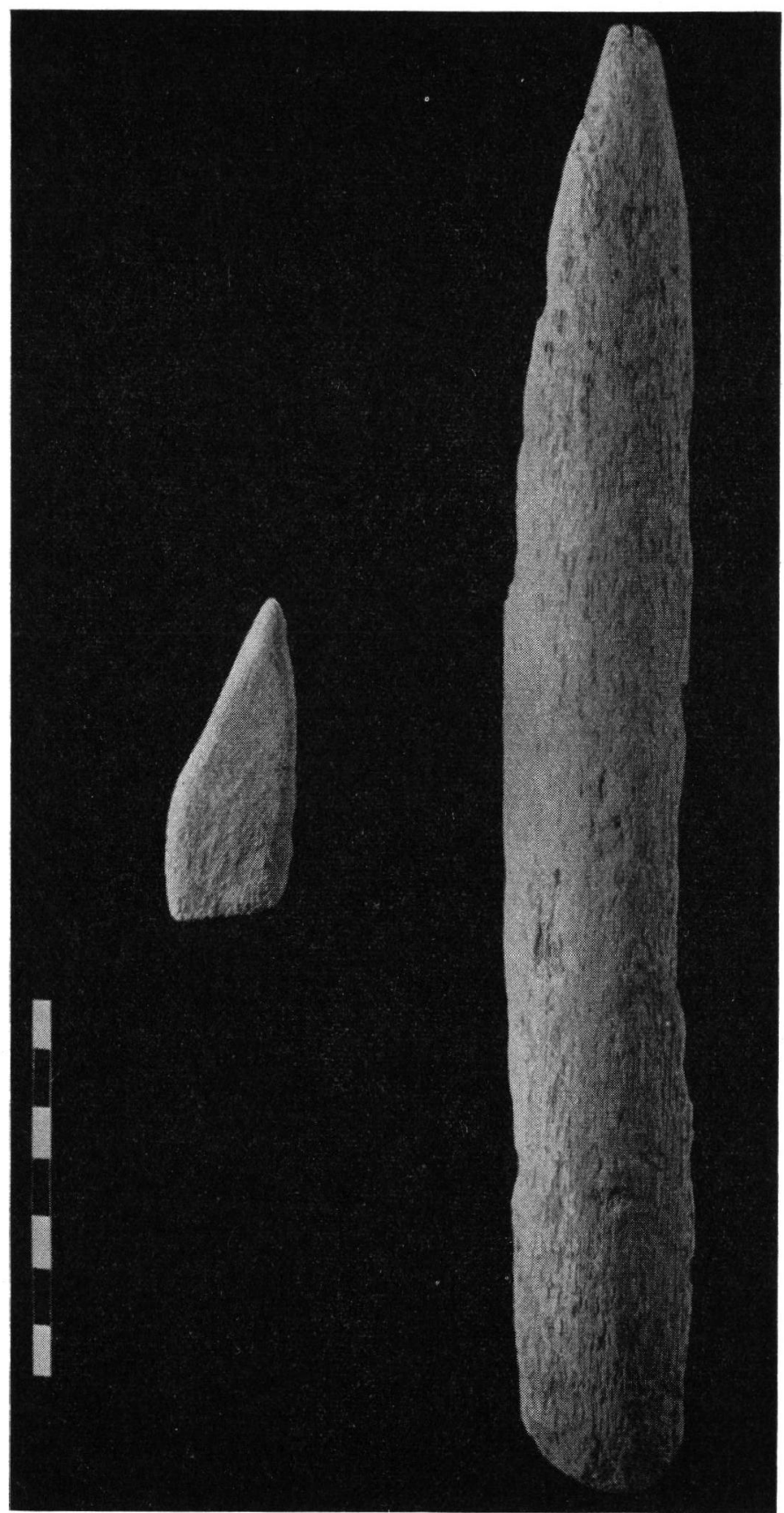

Abb. 4. Knochengeräte aus einem altpaläolithischen Inventar des Unteren Würm (Stetten/Lonetal, Vogelherd, Schicht VI).

(Foto H. Hell, Tübingen). lich des Rheines erst mit Erschëinen des echten Aurignacien kennen. Ob dadurch im östlichen Altpaläolithikum primäre Entwicklungstendenzen oder nur sekundäre Beeinflussungen durch andere relativ alte „jungpaläolithischere“ Kulturkörper in Erscheinung 
treten, ist beim gegenwärtigen Stand der Materialverarbeitung nicht zu entscheiden. Die oben bereits erwähnte Kratzerentwicklung stellt dagegen zumindest bereits seit dem Ausgang der vorletzten Kaltzeit (Hj. MüLLER-BECK 1956) eine ganz allgemeine Entwicklungstendenz im europäischen Altpaläolithikum dar.

Wir dürfen also zusammenfassend feststellen, daß die in Süddeutschland auftretende Gruppe altpaläolithischer Inventare mit hohen Kratzeranteilen, auch wenn sie Knochenspitzen und ähnliche Knochengeräte führen, noch nicht dem Jungpaläolithikum zugeordnet werden können. Dabei soll allerdings kein abschließendes Urteil über die Beziehungen dieser Gruppe zum echten Aurignacien gefällt werden. Bei einer vorläufig weder zu beweisenden noch aber auszuschließenden Gleichzeitigkeit dieser beiden Komplexe besteht immerhin die Möglichkeit eines wenigstens teilweisen Einflusses durch die technisch fortschrittlichere Industrie.

Neben den bisher genannten Artefaktkomplexen aus dem Übergang zur letzten Kaltzeit in Süddeutschland muß eventuell noch eine jüngere Stufe des Altpaläolithikums mit Faustkeilschabern hierher gestellt werden, wie sie möglicherweise in den Funden der Klausennische (H. Obermaier \& P. Wernert 1914, 1929) vorliegt (Abb. 3). Eine Entscheidung über die Zeitstellung dieser Gruppe ist wegen des Fehlens zuverlässiger stratigraphischer Anhaltspunkte nicht zu fällen. Immerhin sei darauf hingewiesen, daß die dort vorliegenden Funde einige typologische Verschiedenheiten gegenüber den ähnlichen Funden aus dem Ende der vorletzten Kaltzeit aufweisen, die nicht allein durch den vorhandenen Unterschied des Rohmaterials erklärbar sind.

Trotz aller noch zu lösender Aufgaben wird doch bereits jetzt schon deutlich, wie bunt und vielfältig das kulturelle Bild des süddeutschen Altpaläolithikums im Anfang der letzten Kaltzeit zu werden beginnt. Die Situation kompliziert sich weiterhin dadurch, daß einerseits bei zunehmender Klimaverschlechterung mit einer Zuwanderung aus Osten abziehender Gruppen zu rechnen ist, während andererseits gleichzeitig ausharrende, aber sich dabei langsam verändernde Reliktkomplexe vorhanden sind, deren Anpassung an die neuen Gegebenheiten in Richtung des Kulturbesitzes der östlichen Neuankömmlinge tendieren dürfte, ein Vorgang, der von Süddeutschland aus allein sicher nicht zu entwirren ist. Erkennbar ist bisher nicht mehr als das Eindringen neuer Faktoren eben aus östlicher Richtung und eine Reihe von Sonderzügen gegenüber den gleichzeitigen altpaläolithischen Provinzen westlich des Rheines.

Die endgültige Ablösung des Altpaläolithikums durch das Jungpaläolithikum wird zwar durch das gut ausgeprägte Aurignacien des Vogelherdes (G. RIEK 1934) angezeigt, ist aber innerhalb der letzten Kaltzeit stratigraphisch nicht eindeutig festzulegen. Es ist möglich, daß diese Ablösung in Süddeutschland im Bereich der letztkaltzeitlichen Hauptschwankung eintrat, aber vorläufig auch nicht ausgeschlossen, daß sie bereits vorher erfolgt war. Daß die Zäsur zwischen Alt- und Jungpaläolithikum westlich des Rheines erst mit dem Ende der Hauptschwankung zusammenfällt, ist zumindest für Nordfrankreich hinreichend belegt (F. BorDEs 1954). In Osteuropa ist die Sachlage vorläufig unklarer und vor allem durch die oben angeführten typologischen Ungenauigkeiten auch grundsätzlich schwieriger. Eine endgültige Lösung ist hier kaum zu erwarten, solange nicht der eigentliche Bildungsherd des Aurignacien abgegrenzt werden kann, der vermutlich räumlich recht ausgedehnt und keineswegs punktförmig klein gewesen sein dürfte. Das untere Vogelherd-Aurignacien (G. RIEK 1934 - Vogelherd V) ist zur Zeit jedenfalls als das typologisch älteste Aurignacien Europas zu bezeichnen. Welche Beziehungen zwischen ihm und dem wahrscheinlich älteren Aurignacien von Jabrud (A. Rust 1950 - Prä-Aurignacien) bestehen, bedarf noch der Überprüfung. Bei derartigen Distanzen, wie sie diese beiden Stationen zueinander aufweisen, reicht die Aussagekraft der archäologischen Inventare im jeweiligen Hangenden und Liegenden der hier 
interessierenden Fundkomplexe, zumal bei Zeitdifferenzen, die unter der Größenordnung von 10000 Jahren liegen dürften, allein nicht mehr aus.

Einigermaßen sicher datierbares Jungpaläolithikum liegt in Süddeutschland erst wieder mit dem Ausgang der letzten Kaltzeit vor, einzelne, mehr sporadische Spuren sind vielleicht älter. Ob bereits das Bölling-Interstadial oder eine noch etwas ältere Oszillation, die möglicherweise als klimatische „Wendemarke“ zu bezeichnen ist, mit süddeutschen jungpaläolithischen Funden in Zusammenhang zu bringen sind, ist vorläufig noch unklar. Komplexe aus dem Ende der Alteren Dryas sind dagegen nachgewiesen (H.-G. BANDi 1954; H. Gross 1955). Ein guter Teil der jungpaläolithischen Stationen Süddeutschlands wird in das eigentliche Alleröd zu setzen sein, in dem zugleich auch der Beginn für die nun nicht mehr abbrechende Begehung des süddeutschen Beckens liegen dürfte. Mit dem Alleröd beginnt aber auch die zunehmende Aufsplitterung der vor allem aus östlichen Quellen stammenden ursprünglichen endpaläolithischen Einheit, die wohl kaum durch den Kälterückfall der Jüngeren Dryas noch einmal hergestellt wurde. Einmal haben wir vom Alleröd $a b$, oder schon etwas früher, mit dem Eindringen westlicher Komponenten nach Süddeutschland zu rechnen (K. J. NARR 1955) und zum anderen bewirkt offenbar die fortschreitende Wiederbewaldung eine Aufsplitterung der ehemals freibeweglichen Jägerkulturen in kleinere, örtlich stärker gebundene Gruppen. Erst mit Beginn des 4. vorchristlichen Jahrtausends endet durch das Eindringen fremder kultureller Errungenschaften und wohl auch Volksgruppen die weitgehend wieder autochthon gewordene Vorherrschaft des Jäger- und Sammlertums.

Bei einer zusammenfassenden Übersicht läßt sich demnach in Süddeutschland als kulturelle Abfolge während des Pleistozäns belegen: An der Basis die Fundstelle von Mauer mit Homo heidelbergensis und frühpaläolithischen Geröllgeräten, verbunden mit altpleistozäner Fauna, offenbar am Ausgang einer langdauernden Warmzeit unter allerdings noch relativ günstigen Umweltsverhältnissen. Darüber, getrennt wahrscheinlich nur durch eine einzige Kaltphase, die Interglazialfunde von Steinheim und die unmittelbar darauf im Beginn des folgenden Frühglazials eingebetteten kleinen Abschlaginventare. In einer Warmschwankung im Ende der anschließenden Kaltzeit Abschlaggeräte mit einem schwachen Faustkeilanklang. Ganz zum Schluß der gleichen Kaltphase, oder besser im Beginn des zugehörigen „Postglazials“, erscheint die ältere Faustkeilschaberstufe. Mehr gegen den oberen Abschnitt des letzten Interglazials altpaläolithische Artefakte mit Blattspitzenandeutungen und der Fauna des ausgehenden Mittelpleistozäns. Im Beginn der letzten Kaltzeit schließlich verschiedene altpaläolithische Gruppen, und dann im Bereich der Hauptschwankung erstes Auftreten des Jungpaläolithikums, ohne daß dieser Vorgang bereits stratigraphisch festlegbar wäre. Im Oberen Würm endlich reines Jungpaläolithikum, das sich mit der zunehmenden Veränderung der klimatischen Bedingungen etwa ab Ausgang der Älteren Dryas regional immer stärker aufspaltet und in holozäne Kulturstufen übergeht.

Sicher zu fassen sind damit in Süddeutschland die beiden letzten Kaltzeiten und die von ihnen eingeschlossene Warmphase: Über warmzeitlichen Spuren, die wahrscheinlich dem faunistisch gut fixierten Steinheimer Interglazial angehören, folgt ein offenbar dreigegliederter kaltzeitlicher Komplex, in dessen oberem Abschnitt eine größere interstadiale Schwankung auftritt. Danach erscheinen die Spuren des Stuttgarter Interglazials und der anschließenden letzten, durch eine etwa hervorgehobene Schwankung zwar unterteilten, aber im ganzen einheitlichen Kaltzeit, sowie der Übergang zu den gegenwärtigen Klimaverhältnissen.

In Süddeutschland ist es natürlich ganz besonders verlockend, eine derartige zunächst nur weitgehend relativ und in sich mehr oder weniger gefangene Gliederung mit allgemeineren stratigraphischen Fixpunkten des Pleistozäns in Verbindung zu bringen. Zur Verfügung ständen dabei in erster Linie die Ergebnisse A. Penck's \& E. BRüCK- 
NER's sowie eine ganze Anzahl von neueren ergänzenden und teilweise auch korrigierenden Beobachtungen. Wenn es auch nicht Sache des Verfassers, dessen Kompetenzen in dieser Hinsicht allzu begrenzt sind, sein kann, eine eingehende Studie hierzu vorzulegen, so sei doch bei dieser Gelegenheit wenigstens der Beginn einer Diskussion versucht, deren Fortführung wünschenswert wäre. Allerdings muß dieser Versuch zunächst grundsätzlich auf den süddeutschen Raum beschränkt bleiben. In anderen Gebieten gewonnene Ergebnisse würden eine zu starke Belastung der sich stellenden Aufgabe mit sich bringen. Nur gelegentlich sei ein Ausblick auf einzelne entferntere Geländebeobachtungen erlaubt. So müssen wir uns also mit einer Einbeziehung der glazialen Verhältnisse im nordwestlichen Teil der Alpen bescheiden, der zudem dem Verfasser als einziger aus eigener Anschauung bekannt ist.

Im vor allem für die allgemeine Stratigraphie der Schotter wesentlichen Illergebiet scheiden heute sowohl I. Schaefer (1953), wie auch H. Graul (1949) nach dem Vorgang von B. EBerL (1930) Schotterglieder aus, die sicher älter anzusetzen sind als Günz im ursprünglichen PENCK'schen Sinne. So unangenehm dies für die gesamte quartäre Terminologie auch sein mag, so unumgänglich scheint doch eine neue Bezeichnung für diese verhältnismäßig alte Kaltphase, wie sie durch B. EBERL (1930) mit „Donau“ eingeführt wurde. Es geht kaum an, den Begriff „Günz" nach dem Vorschlag von H. Gams (1953) auf das Donau B. EberL's auszuweiten, auch wenn dieser neue Begriff Teile des alten Günz in sich faßt. Dazu kommt, daß sehr wahrscheinlich das Verständnis für die pleistozänen Klimaveränderungen durch die richtigere Trennung B. EBERL's erheblich erleichtert werden dürfte. In diesem Zusammenhang sei als Beispiel auf eine Arbeit F. C. Howell's (1955) über die Altersansetzung der Australopithecinen Südafrikas verwiesen. Der hohe Anteil inneralpiner Gerölle spricht für eine kaltzeitliche Stellung der Donau-Schotter. Zugehörige Moränen sind allerdings bisher unbekannt. Eine gewisse Vielgliedrigkeit dieser Phase wird durch die Unterteilung der Schotterfolge selbst (I. Schaefer 1953) wahrscheinlich gemacht, auch trotz der durch P. BECK (1954; in H. Graul 1954) vorgenommenen Einschränkung in Hinsicht auf die schottermorphologische Überempfindlichkeit des Iller-Lechgebietes. Die südwestlich des Rheines auftretenden Sundgauschotter sind vielleicht als gleichzeitig zu den ältesten pleistozänen Schottern des Illergebietes anzusehen.

Auf dieses unterste Schotterglied folgen dort und auch an anderen Stellen (zumindest) zwei weitere Schotterkörper, die sich von denen der Donau-Phase durch ihren geringen Anteil inneralpiner Gerölle unterscheiden (B. EBERL 1930; I. SChaEfer 1953). Es handelt sich um die klassischen Deckenschotter und die hierher gehörigen Varianten. Wieweit eindeutig zu ihnen gehörige Moränen nachweisbar sind, ist gegenwärtig nicht sicher zu übersehen. Möglicherweise steht die von A. PENCK $(1901 / 09$, I, 1) als Günz klassifizierte Moräne bei Hof und Schloß Wagegg in diesem Zusammenhang. Besonders überprüfungsbedürftig scheinen aber nach den Hinweisen H. GRauL's (1955) alle mit jüngeren Deckenschottern in Verbindung gebrachten Mindel-Moränen zu sein. Bei dieser Sachlage wollen wir die zu den beiden Deckenschottern gehörigen Klimaphasen zur Vorsicht vorläufig - wenn auch in gewisser Anlehnung an die gebräuchliche Terminologie - mit den Buchstaben $G$ und $M$ bezeichnen. Ihr zeitlicher Abstand zur älteren Donau-Kaltzeit ist unbekannt, ebenso wie der Umfang der zugehörigen Klimaverschlechterung. Ob die umstrittenen Funde von Holziken (H. G. STEHLIN 1922) wenigstens in Richtung der klimatischen Deutung weiterhelfen können, muß hier dahingestellt bleiben. Anzunehmen ist dagegen auf Grund der Schotteranalysen im Iller-Lechgebiet, daß beide Deckenschotterglieder Abkühlungsoszillationen angehören dürften, die relativ geringer als Donau gewesen sind. Alle drei altpleistozänen Schottergruppen werden durch klare Erosionen voneinander getrennt, ohne daß deren zeitliche Dauer aber bisher irgendwie sicher faßbar gewesen wäre. Zwischen den jüngeren Deckenschottern und den 
folgenden glazialen Serien liegt im Rhone-, Aare- und Rheingletscherbereich eine klare und eindeutige Zäsur, die auch durch die Beobachtungen H. GrauL's (1955) im IllerRißgebiet erscheint, wo sie allerdings I. SCHAEFER (1953, unter Einbeziehung des Lechgebietes) als nicht so eindrücklich ansieht.

Eine neue, offenbar vollständig selbständige Kaltzeit tritt nach Feststellungen H. Graul's (1955) möglicherweise innerhalb des alten Riß-Komplexes in Erscheinung, die folgerichtig aus ihm auszuklammern wäre. Auf eine vielleicht hierher gehörige Beobachtung, die durch E. Gerber $(1941,1950)$ bei der Aufnahme des Blattes Fraubrunnen/Wynigen/Hindelbank/Burgdorf des Geologischen Atlasses der Schweiz gemacht wurde, sei an dieser Stelle hingewiesen. Wenn sich eine derartige Abtrennung als richtig erweisen sollte, wären wohl ein großer Teil der älteren Rißbildungen in diese neue, selbständige Kaltzeit zu verweisen. Daneben erscheint es aber durchaus nicht ausgeschlossen, daß manche, vor allem glazigene Spuren, die dem bisherigen Mindel zugeordnet werden, ebenfalls hierher gehören. Auch wenn zunächst weitere Unterstützungen dieser Hypothese abgewartet werden müssen, so soll doch der damit gegebene Abschnitt unter Andeutung seiner Stellung im bisherigen System provisorisch mit dem Buchstaben $\mathrm{N}$ gekennzeichnet werden. Es ist unter Umständen denkbar, daß ein neugefaßter Begriff des „Mindel“ als Bezeichnung der N-Kaltzeit verwendet werden könnte, was aber eine Umbenennung der Bildungsperiode der Jüngeren Deckenschotter erforderlich machen dürfte. $\mathrm{Zu} \mathrm{N}$ gehörende Moränenreste liegen offenbar vor. Bezeichnend scheint aber vor allem, daß die im Illergebiet zu N gestellten Schotter (H. Graul 1955 - Altriß) wieder größere inneralpine Geröllanteile aufweisen, sich also stärker von den eigentlichen Deckenschottern im eingeengten Sinne ( $G$ und $M$ ) unterscheiden, dagegen aber gewisse Anzeichen einer Ahnlichkeit mit den Donau-Schottern erkennen lassen.

Auf diese N-Schotter folgen die übrigen bisher im allgemeinen dem Riß zugeordnete Schotter, die eine deutliche Zweiteilung aufweisen (H. Graul 1955). Sie sind durch hohe inneralpine Geröllanteile im Illergebiet gekennzeichnet und sind ganz generell mit den Altmoränen der Maximalstände und den sogenannten Jungriß-Moränen zu verbinden. Zwischen den beiden Schotterkomplexen liegt ein deutlicher Einschnitt, dessen Charakter vorläufig noch nicht geklärt ist und der sowohl einem Interstadial wie einem Interglazial angehören könnte. H. GRAUL (1955) neigt offenbar eher einer Interpretation als Interglazial zu. Die entsprechenden Schotterkörper im Bereich des Rhone-AareGletschers scheinen dagegen mehr für die Annahme eines, wenn allerdings auch gut ausgeprägten Interstadials zu sprechen. Hier soll dieser Komplex vorläufig zusammengefaßt als $\mathrm{R}$ bezeichnet werden, da er in dieser Einengung auf keinen Fall mehr der alten Rißeiszeit im Sinne von A. PENCK entspricht. Die jüngste, wieder durch eine Erosion und eindeutige Verwitterungsdecke abgetrennte Schotterphase wird durch die würmzeitliche Akkumulation gebildet, deren Einheitlichkeit im gröberen Sirine sicher erscheint, wenn auch eine gewisse Zweiteilung (etwa H. Graul \& I. SChaefer 1953) noch diskutiert wird, die aber keine Verteilung der gesamten Akkumulation auf zwei warmzeitlichinterglazial getrennte Kaltzeiten rechtfertigen könnte. Das würmzeitliche Moränenproblem dagegen muß als immer noch nicht eindeutig gelöst betrachtet werden. Die erhaltenen Rückzugsstände der weichenden Würmgletscher sind derart zahlreich, daß jeder möglicherweise älterer Stand des Eises nur außerordentlich schwer klar erkennbar wird. Bisher gibt es jedenfalls noch keine einzige Altwürm-Moräne aus der Vorstoßzeit, die einhellige Zustimmung bei allen zum Urteil am ehesten berechtigten Feldforschern gefunden hätte. Gerade hier scheinen großzügige Neuaufnahmen über weite und möglichst zahlreiche Gletschergebiete erforderlich, um der noch im Gange befindlichen Diskussion Vergleichsmaterial zur Verfügung zu stellen.

Wenn wir unter den gegebenen Verhältnissen die Bereiche der Gletscher- und Schotterforschung mit vielen unbeantworteten Fragen verlassen und auf neue Untersuchungen 
der Zukunft hoffen müssen, so betreten wir mit dem Gebiet der Lößforschung ein gerade in den letzten Jahren intensiv bearbeitetes Gelände. Die ältesten bisher in Europa bekannten Lösse wurden im Rhonetal beobachtet und enthalten eine VillafranchianoFauna (J. VIRET 1948; F. Bourdier 1953), die einen Zusammenhang dieser Ablagerungen mit der Donau-Kaltzeit relativ wahrscheinlich werden lassen. Entsprechungen hierzu fehlen in Süddeutschland, wie auch in allen übrigen europäischen Lößzonen bisher ganz. Weiter verbreitet, wenn auch selten erhalten, ist der „Alteste Löß“ (Freising's Löß I, 1951), der meist nur als Ausgangsprodukt einer unter Löß begrabenen fossilen Bodenbildung in Erscheinung tritt und noch keine Artefaktfunde geliefert hat. Über diesem „Altesten Löß“ folgt ein weiterer mit altpaläolithischen Artefakten (Böckingen, Abb. 1) verbundener Löß (FREISING's Löß II), der von einer weiteren fossilen Bodenbildung und dem anschließenden letzten, zweigeteilten Löß (FREIsING's Löß III) überlagert wird (im einzelnen dazu die bereits oben genannten Arbeiten: H. FreIsING 1949, 1951; F. WEIDenbach 1952; K. Brunnacker 1953, 1956; J. Fink 1956). Auffallend ist, daß den genannten vier Lößkomplexen möglicherweise vier als kaltzeitlich im weiteren Sinne anzusprechende Schotterfolgen gegenüberstehen. Wie wir gesehen haben, könnte der früheste, in Süddeutschland nicht belegbare Löß mit der Donau-Phase in Verbindung stehen. Die oberen drei Lösse, deren Aufeinanderfolge ohne Fehlen eines kaltzeitlichen Zwischenkomplexes wohl als sicher angesehen werden darf, könnten den drei jüngeren unmittelbar aneinanderschließenden Schotterzyklen im Rhone-Aare- und Illergebiet entsprechen. Das hieße aber, daß der „Alteste Löß“ (I) unserer Phase N, der "Altere Löß“ (II) unserer Phase R und der "Jüngste Löß“ (III) dem Würm in den Moränen und glazigenen Schottern gleichgesetzt werden müßte.

Ahnlich kurz können wir uns bei der allgemeinen Besprechung der Höhlensedimente fassen. Vorausgeschickt werden muß allerdings, daß bei der Bildung von Höhlensedimenten gewisse Gesetzmäßigkeiten inzwischen als gesichert gelten können. Die ersten Überlegungen H. Freising's (1954) hierzu konnten durch weitere Geländebeobachtungen und Profilinterpretationen hypothetisch ausgedehnt werden ( $\mathrm{Hj}$. MüLLER-BECK 1956) und wurden inzwischen durch die detaillierte Untersuchung eines Einzelprofils (K. BRUNNACKER 1956a) zuverlässig erfaßt. Es handelt sich im wesentlichen um Folgendes: Höhlensedimente sind wie alle Akkumulationsbildungen während der Warmphasen des Pleistozäns intensiven Verwitterungsvorgängen unterworfen. Unter Veränderung der primären Schuttbestandteile entstehen Schuttböden in einer Reihe von Variationen, die den jeweiligen Ausgangsmaterialien entsprechen. Mit Beginn einer Klimaverschlechterung und der mit ihr in Zusammenhang stehenden Denudation, Erosionsveränderung und $\mathrm{Zu}$ nahme der Frostwirksamkeit geraten Hangschuttablagerungen - zu denen die Sedimente vor allem im Eingangsbereich von Höhlen zu rechnen sind - ganz allgemein in verstärkte Bewegung. Auf eine anfängliche Abtragung folgt mit allmählicher Verlangsamung der Bewegung in späteren Abschnitten der Kaltzeit eine Aufschüttung ursprünglich höher am Hang gelagerter Schuttmassen. Dem entspricht zunächst eine Ausräumung der Höhlen und eine anschließende Einlagerung höhlenfremder Verwitterungs- und Schuttmaterialien aus höher liegenden Hangteilen oder unter Umständen auch aus hangaufwärts befindlichen Höhlen. Ein völliges Aufhören dieser Verlagerungen dürfte wegen der fehlenden Festlegung durch Bewuchs überhaupt nicht anzunehmen sein. Diese Gesetzmäßigkeit gilt selbstverständlich nur für das jeweilige periglaziale Gebiet und variiert örtlich entsprechend den topographischen Verhältnissen in der Umgebung einer Höhle und auf Grund einer Anzahl weiterer Faktoren jeweils stark. Die weitgehende Festlegung des Schuttes während der eigentlichen Kaltzeit im engeren Sinne entspricht etwa der des Lösses, bleibt aber wie diese von den allgemeinen Geländeverhältnissen der Umgebung abhängig. Erst die Erosionserscheinungen im Ausgang einer Kaltzeit rufen eine neue Verstärkung der Hangschuttbewegungen hervor, deren Umfang aber durch 
die beginnende Wiederbewaldung und das Nachlassen der Frostauswirkungen hinter dem der frühglazialen Verlagerungen erheblich zurückbleibt.

Es ist anzunehmen, daß derartige Schuttsedimentationsfolgen, wenn auch in verschiedener Feingliederung, in jeder pleistozänen Kaltphase zur Ausbildung gekommen sind. Trotzdem ist es aber vorläufig keineswegs möglich, alle bisher genannten Kaltzeiten in Höhlensedimenten zu erfassen. Offenbar erschwert die mehrfach wiederholte Ausräumung und anschließende Überlagerung die Beobachtung älterer erhaltener Schuttfolgen ganz erheblich. Immerhin scheinen Teile einer altpleistozänen Folge in verschiedenen Höhlensedimenten erhalten geblieben $\mathrm{zu}$ sein, von denen hier dasjenige von der Erpfingerhöhle (U. LEHMANN 1953) als Neubearbeitung erwähnt werden soll. Es ist nicht ganz undenkbar, daß gerade dieses Sediment einer Verlagerungsperiode angehört, die mit der frühpleistozänen Donau-Kaltzeit zusammenfallen könnte. Die relativ häufige Erhaltung derartiger Sedimente innerhalb sehr alter pleistozäner Erosionssysteme, die sich von jüngeren stets scharf absetzen, wäre durch eine starke Veränderung des gesamten Entwässerungssystems in einer anschließenden ausgedehnten Warmzeit recht einleuchtend erklärbar. Endgültige Schlüsse in dieser Beziehung sind aber vorläufig noch verfrüht.

Höhlensedimente aus G, M und $\mathrm{N}$ sind bisher unbekannt. Wieweit derartige Schuttakkumulationen in $G$ und $M$ überhaupt auftraten, muß dahingestellt bleiben. Im kälteren $\mathrm{N}$ dagegen sollte die Ausbildung eines Schuttzyklus erfolgt sein. Dies war wahrscheinlich auch der Fall, aber die hierher gehörigen Sedimente wurden durch die Auswirkungen der beiden unmittelbar anschließenden Kaltzeiten weitgehend zerstört oder doch so erheblich überdeckt, daß sie bisher noch nirgends angefahren worden sind. Auch R-zeitliche Höhlensedimente sind offenbar nur außerordentlich selten erfaßbar. Die bekannte Station von La Micoque enthält eine wahrscheinlich sehr vollständige hierher gehörige Schuttbildung mit reichen Artefakteinschlüssen, die etwa mit dem Frühglazial von $\mathrm{R}$ beginnt und nach Ausbildung einiger folgender Unterglieder durch die Verwitterung des letzten Interglazials nach oben abgeschlossen wird (Abb. 1). Darüber folgt noch einmal ein gering-mächtiger Kaltschutt aus dem Beginn des Würm, dessen Ablagerung durch den noch im gleichen Frühglazial erfolgenden Einsturz des Höhlendaches zum Abschluß kommt. Die Erhaltung und leichte Zugänglichkeit dieses Sedimentes ist neben besonderen Abdämmungsverhältnissen am Hangfuß auf jenen Einsturz zurückzuführen.

In Süddeutschland kann bisher nur der untere Teil des Bocksteinschmiedenprofiles als Beispiel einer R-zeitlichen Hangschuttbildung betrachtet werden. Die Schutteinlagerung, der eine Ausräumung vorausgegangen sein dürfte, beginnt irgendwann im Frühglazial noch gleichzeitig mit einer altpaläolithischen Begehung Süddeutschlands. Über die Vollständigkeit und Untergliederung der folgenden Sedimentteile wird erst die Publikation der während der Grabung gemachten Einzelbeobachtungen Aufschluß geben. Der obere Teil der noch R-zeitlichen Folge darf mit ziemlicher Sicherheit ebenfalls in das zugehörige Spät- oder beginnende Postglazial gestellt werden. Die Geräte der Faustkeilschaberstufe dürften in dieser Phase, die etwa der klimatischen Umwelt des Mesolithikums im beginnenden Holozän entsprechen wird, zur Einbettung gelangt sein. In einer Zeit also, die als Beginn des Stuttgarter Interglazials anzusehen wäre.

Wahrscheinlich unvollständige R-zeitliche Höhlensedimente liegen außerdem auch im Vogelherd (G. RIEK 1934) vor, die hier aber nicht noch einmal im Detail besprochen werden sollen (Hj. MüLler-BECK 1955, 1956). Nach den Artefaktfunden können Teile der spätglazialen R-zeitlichen Sedimentbildungen erhalten geblieben sein (Abb. 1), während alle interglazialen Verwitterungsprodukte auch in den Höhleneingängen, wo sie sehr wahrscheinlich am mächtigsten entwickelt waren, abgebaut worden sind und durch regional begrenzte Einlagerungen höhlenfremder, verfrachteter Verwitterungslehme ersetzt wurden (H. FREISING 1954). 
Sehr viel häufiger dagegen sind Sedimentbildungen in Höhlen, die den Anfängen des Würm zuzuweisen sind. Nahezu alle altpaläolithischen Inventare Süddeutschlands, die in Höhlen gefunden wurden, stammen aus derartig zu datierenden Ablagerungen, deren häufige Erhaltung durch das Fehlen stärkerer folgender Hangschuttbewegungen erklärbar wird. Gelegentlich werden in den hierher zu stellenden Einbettungssedimenten, die im allgemeinen überwiegend höhlenfremder Herkunft sind, autochthone Schuttanteile sichtbar,wie dies offenbar in Mauern (Abb. 1) der Fall zu sein scheint (A. BoHMERs 1951; G. FREUND 1955). Die Tatsache der frühglazialen Schuttbewegungen sollte vor allem bei Anwendung der Korngrößenanalyse in Höhlensedimenten berücksichtigt werden. Offenbar wird relativ häufig eine durch Veränderung der Schuttbewegung hervorgerufene Verschiebung der Korngrößenverteilung als klimatisch unmittelbar bedingter Vorgang aufgefaßt. Die Zunahme des Feinkornanteiles zum Beispiel muß nicht immer ausschließlich als Beleg einer Erwärmung anzusehen sein, sondern es besteht ebenso gut die Möglichkeit, daß dadurch das Nachlassen einer vorher stärkeren Hangschuttbewegung zum Ausdruck kommt. Derartige Bewegungen, die grundsätzlich zwar auch klimatisch bedingt sind, besitzen aber zusätzlich eine derartige Abhängigkeit von kleinräumlichen Gegebenheiten, daß geringere klimatische Oszillationen nur außerordentlich schwer erkennbar sein dürften. So sind denn auch bisher eindeutig zwischen Kaltschutt stehende Interstadiale in Höhlensedimenten aus der letzten Kaltzeit nirgends zuverlässig nachgewiesen worden. Vielleicht deutet sich in der Schicht D (A. BoHMERs 1951) von Mauern (G. Freund 1955; Hj. Müller-Beck 1956) und in der Schicht C (Hj. Müllek-Beck 1956) der Kleinen Ofnet eine derartige Schwankung durch zunehmende Fließbewegungen an. Alle angeblichen Interstadiale dagegen, die unmittelbar an der Oberkante der stärker verlagerten Basissedimente scheinbar nachweisbar sind, müssen, nach den angeführten Gesichtspunkten, als eher unsicher betrachtet werden. Als Beispiel einer lang anhaltenden Sedimentbewegung im Beginn des Würm sei hier der Hohle Stein bei Schambach (K. Gumpert 1952, 1953; K. BrunnaCKer 1956a) erwähnt.

Ebenso abhängig von der Geländeform der Umgebung sind Schuttverlagerungen im Spät- und frühen Postglazial. Die Anfänge dieser Bewegungen liegen in einer Reihe von Höhlen offenbar noch vor dem Ende der Älteren Dryas und dauern bis über die Jüngere Dryas hinaus an, ja, reichen gelegentlich noch weit darüber hinauf. Im allgemeinen werden aber diese letzten Hangschuttbewegungen durch das Einsetzen der Wiederbewaldung und das Aufhören des dauernden Bodenfrostes bald zum Stillstand gebracht. Auffallend ist die Beschränkung der spät- bis postglazialen Hangschuttverlagerungen auf den unteren Teil der Hänge, die sehr viel häufiger durch Erosionen als durch Akkumulationen zum Ausdruck zu kommen scheinen. Höher oder in hängenden Tälern gelegene Höhlen zeigen nur gelegentlich eine geringe Beeinflussung. Nicht ohne Grund stammen die altpaläolithischen Funde aller periglazial beeinflußter Gebiete vor allem aus derartigen Höhlen.

Zum Abschluß wollen wir noch einen Blick auf die paläontologischen Verhältnisse während des Pleistozäns in Süddeutschland werfen, wie sie vor allem durch neuere Arbeiten zum Ausdruck kommen (K. D. AdAM 1952, 1953, 1954; F. HELler 1955; S. Kuss 1955; U. Lehmann 1953, 1954). Die älteste pleistozäne Fauna wird durch die Funde von Erpfingen repräsentiert (U. LenmanN 1953). Ihre exakte stratigraphische Stellung ist vorläufig nicht gesichert. Es könnte aber sein, daß gewisse Beziehungen zur DonauKaltzeit bestehen. Am Ende einer offenbar längeren altpleistozänen Warmphase stehen die noch mit Flußpferd verbundenen Tierreste von Mauer (S. Kuss 1955), die etwa Jockgrimm 2 im für das Flußpferd ökologisch günstigeren Gebiet entsprechen (K. D. Adam 1953; S. Kuss 1955). Darüber folgen kältere Faunen, deren zeitliche Dauer bisher nicht recht abzuschätzen ist, d. h. es ist nicht klar, ob sie eine ganze Kaltphase durchgängig belegen, oder aber nur deren Anfang und Ende. Hierher gehören die Faunen 
aus den mittleren und oberen Schichten von Mosbach (K. D. ADAM 1952,1953) sowie den Alteren Mammut-Schottern von Steinheim (K. D. ADAM 1954). Eine eindeutige interglaziale Warmzeit, die wir zwischen unsere $\mathrm{N}$ - und R-Phase stellen müssen, liegt in der Tiergesellschaft der Waldelefanten-Schotter von Steinheim vor (K. D. Adam 1954). Im Zusammenhang mit der R-Kaltzeit, offenbar wieder ohne ihren gesamten Zeitraum zu belegen, kommt eine weitere Kaltfauna vor, wie sie etwa in den Haupt-MammutSchottern von Steinheim (K. D. ADAM 1954) in Erscheinung tritt. Ein weiteres, an R anschließendes Interglazial wird durch die faunistischen Funde von Stuttgart-Cannstatt (K. D. Adam 1953b) und Stuttgart-Untertürkheim (F. Berckhemer 1935) gesichert. Der Übergang zur letzten Kaltphase, dem Würm, wird dank der verbesserten Erhaltungsbedingungen vielfältig erfaßbar, ebenso wie diese Kaltzeit selbst, die offenbar ziemlich durchgängig mit faunistischen Resten belegbar ist. Als Beispiel für ein an Tierfunden reiches würmzeitliches Sediment in Süddeutschland sei hier das von F. HELler (1955) bearbeitete Material von Mauern angeführt. Eindeutige faunistische Belege für eine ausgeprägtere klimatische Schwankung innerhalb des süddeutschen Würm treten bisher an keinem einzigen Fundplatz auf. Das bedeutet aber, daß die innerhalb des Würm liegende Hauptschwankung, die in den Lössen in Erscheinung tritt, in Süddeutschland kaum mit einer stärkeren Klimaumkehr in Zusammenhang gebracht werden muß.

Eine Zusammenfassung aller bisher angeführten Einzelfaktoren - aus denen die Paläobotanik und Mikropaläontologie wegen des geringen Umfanges der hierzu aus Süddeutschland vorliegenden Arbeiten vorläufig ausgeschlossen bleiben muß - ergibt als Anhaltspunkte für die süddeutsche pleistozäne Stratigraphie Folgendes: Als erste stärkere Klimaverschlechterung dürfte im Früh-Pleistozän die Donau-Kaltzeit anzusehen sein. Ihr gehören die ältesten pleistozänen Schotterablagerungen in den nordwestlichen Alpen und der älteste Rhonetallöß an, sowie offenbar auch die frühesten pleistozänen Höhlenablagerungen. Wenn auch die donauzcitlichen Schotter relativ viel inneralpines Geröllmaterial mitführen, so ist dies doch nicht unbedingt ein eindeutiges Zeichen für eine besonders starke Intensität der zugehörigen Klimaverschlechterung. Handelt es sich doch sehr wahrscheinlich um den ersten Eistransport nach der Alpenauffaltung überhaupt, der sicher stark exponierten zentralalpinen Schutt erfassen konnte und zudem keine tiefe Zertalung des Vorlandes überwinden mußte. Die beiden Deckenschotterkomplexe setzen sich zwar von der älteren Donau-Kaltzeit deutlich ab, doch sowohl ihr klimatischer Charakter, wie auch ihre stratigraphische Stellung sind vorderhand noch unklar. Es scheint deshalb am besten, die möglicherweise zugehörigen Oszillationen $G$ und $M$ mit den zwischen Donau und unserer Kaltphase $N$ stehenden Warmzeitabschnitten vorläufig $\mathrm{zu}$ einer größeren Einheit zusammenzufassen. Am Ende dieser Einheit, die wohl besser überhaupt als größere, durch kleinere Kälteoszillationen leicht unterteilte altpleistozäne Warmphase aufgefaßt werden kann, erscheint die Fundstelle von Mauer und der damit bisher älteste Beleg der Anwesenheit des Menschen in Süddeutschland. Offen bleiben muß allerdings, wie weit die dort auftretenden Geröllgeräte zeitlich nach rückwärts reichen. Es wäre bei den offenbar zuvor herrschenden Klimabedingungen keineswegs allzu überraschend, wenn sich ein erhebliches Alter derartiger oder ähnlicher Inventare ergeben würde.

Die Kaltphase $\mathrm{N}$ ist durch Lösse, Schotter und vielleicht auch Moränebildungen belegt. Funde, die auf eine paläolithische Begehung Süddeutschlands in dieser Zeit schließen lassen, besitzen wir vorläufig nicht. Nach den allerdings keineswegs sicher datierten Funden Nordfrankreichs (H. BreuIL \& $\mathrm{H}$. KELLEY 1954) müßte etwa mit dem Beginn der Faustkeilentwicklung im Anfang von $\mathrm{N}$ gerechnet werden. Aus dem folgenden Steinheimer Interglazial sind bisher keine süddeutschen Artefaktfunde bekannt, dagegen liegt im Menschen von Steinheim wenigstens der Träger einer damals sicher bestehenden, aber in ihrem Charakter noch unbekannten Kultur vor. Aus dem Beginn des 
offenbar mindestens dreifach gegliederten, sowie durch Schotter, Moränen und Lösse belegten $\mathrm{R}$ kennen wir die ersten einfachen Abschlaginventare. In einer Schwankung größeren, interstadialen Ausmaßes gegen das Ende dieser Kaltzeit erscheint eine weitere Abschlagkultur mit ganz schwachen Faustkeilanklängen. Im spätesten Abschnitt der RKaltzeit, oder vielleicht schon im Anfang des anschließenden Postglazials, tritt eine von ähnlichen westlichen Komplexen deutlich abgesetzte Faustkeilschabergruppe auf, die erstmals gewisse eigenständige Züge im süddeutschen Paläolithikum erkennen läßt. Das letzte Interglazial steht mit den mousteroiden, leichte Blattspitzentendenz besitzenden Artefaktfunden in Zusammenhang. Über das wahrscheinlich schon relativ bunte kulturelle Bild dieser letzten Warmzeit fehlt uns wegen des Ausfalles weiterer Funde jede Urteilsmöglichkeit.

Mit dem Beginn des Würm steigt die Zahl der paläolithischen Inventare sprunghaft an, und neben einer Reihe unterschiedlicher Kulturgruppen werden eine ganze Anzahl von Bewegungskomponenten erkennbar. Auffallend ist die stark zunehmende Blattspitzenentfaltung, deren Spuren östlich des Rheins bis zum Ende des Paläolithikums nie mehr völlig verloren gehen. Die Frage der Ablösung des Alt- durch das Jungpaläolithikum muß in Süddeutschland vorläufig noch offen bleiben. Stratigraphisch gesicherte Anhaltspunkte dazu sind noch nicht bekannt. Allerdings ist der zur Verfügung stehende Zeitraum immerhin auf den zweiten Abschnitt des Unteren Würm unter Einschluß der folgenden Hauptschwankung zu beschränken. Der absolute Klimacharakter der Hauptschwankung selbst, die im Löß und vielleicht auch in Höhlensedimenten erkennbar wird, ist vorläufig nicht völlig zu sichern. Alle Anzeichen in Süddeutschland sprechen aber dafür, daß die Hauptschwankung nur mit einer relativ geringfügigen Klimaverbesserung von nicht sehr erheblicher Dauer zu verbinden sein kann. Die Gefahr einer Verwechslung mit dem letzten Interglazial erscheint ebenso wie in Frankreich völlig ausgeschlossen. Auch die bisher aus Osteuropa vorliegenden Zeugnisse sprechen nicht für eine besondere Intensität der Hauptschwankung in Würm. Das gilt auch für die in Istállóskő erfaßte Schwankung, deren Gleichzeitigkeit mit der Hauptschwankung hier allerdings nicht entschieden werden soll (L. VÉRTEs 1955). Die faunistischen Veränderungen sind geringfügig und übersteigen wohl kaum das, was in Süddeutschland in dieser Beziehung zu erwarten sein dürfte. Ahnlich verhält es sich mit dem Wechsel der Bewaldung, die, vor allem wenn man die noch keineswegs extremen Kältewerte im Unteren Würm im Auge behält, kaum allzu gravierend sein dürfte. Auf die mit „subtropischen“ Klimawerten verbundene Berechnung der absoluten Dauer der Schwankung einzugehen, dürfte sich erübrigen. Die Gliederung des Oberen Würm ist ebenfalls noch weitgehend offen. $\mathrm{Daß}$ weitere allgemeine klimatische Schwankungen $\mathrm{zu}$ erwarten sind, darf als bewiesen angesehen werden. Erst mit Einsetzen der großen durchgängigen, etwa mit Bölling oder dem Ende der Alteren Dryas beginnenden Pollenspektren haben wir erstmals gesicherten Boden unter den Füßen. Allerdings bedeutet das nicht, daß alle spätglazialen quartärgeologischen Erscheinungen deshalb schon mit der Vegetationsentwicklung zuverlässig in Verbindung zu setzen sind. Der absolute Rahmen aber ist mit Alleröd, Jüngerer Dryas und echtem Postglazial (H. Gross 1955) wenigstens gegeben und wird durch $\mathrm{C}^{14}$-Datierungen noch zusätzlich verstärkt (K. O. MüNNICH 1956).

Wenn auch vorläufig eine ganze Anzahl der angeführten Parallelisierungen der weiteren Uberprüfung bedarf, so ergibt sich doch mit Hilfe der zeitlich klar getrennten paläolithischen Inventare wenigstens ein grobes Gerüst für die pleistozäne Stratigraphie in Süddeutschland (Abb.5). Die erste pleistozäne Kaltzeit (Donau) hat in Süddeutschland bisher keine menschlichen Spuren geliefert, könnte aber möglicherweise mit Geröllkulturen in Zusammenhang stehen. Ein Geröllinventar erscheint eindeutig am Ende einer bisher in sich nicht zu gliedernden, wahrscheinlich aber lang dauernden altpleistozänen Warmphase. Westlich unseres Raumes mag etwa gleichzeitig die Faustkeilent- 


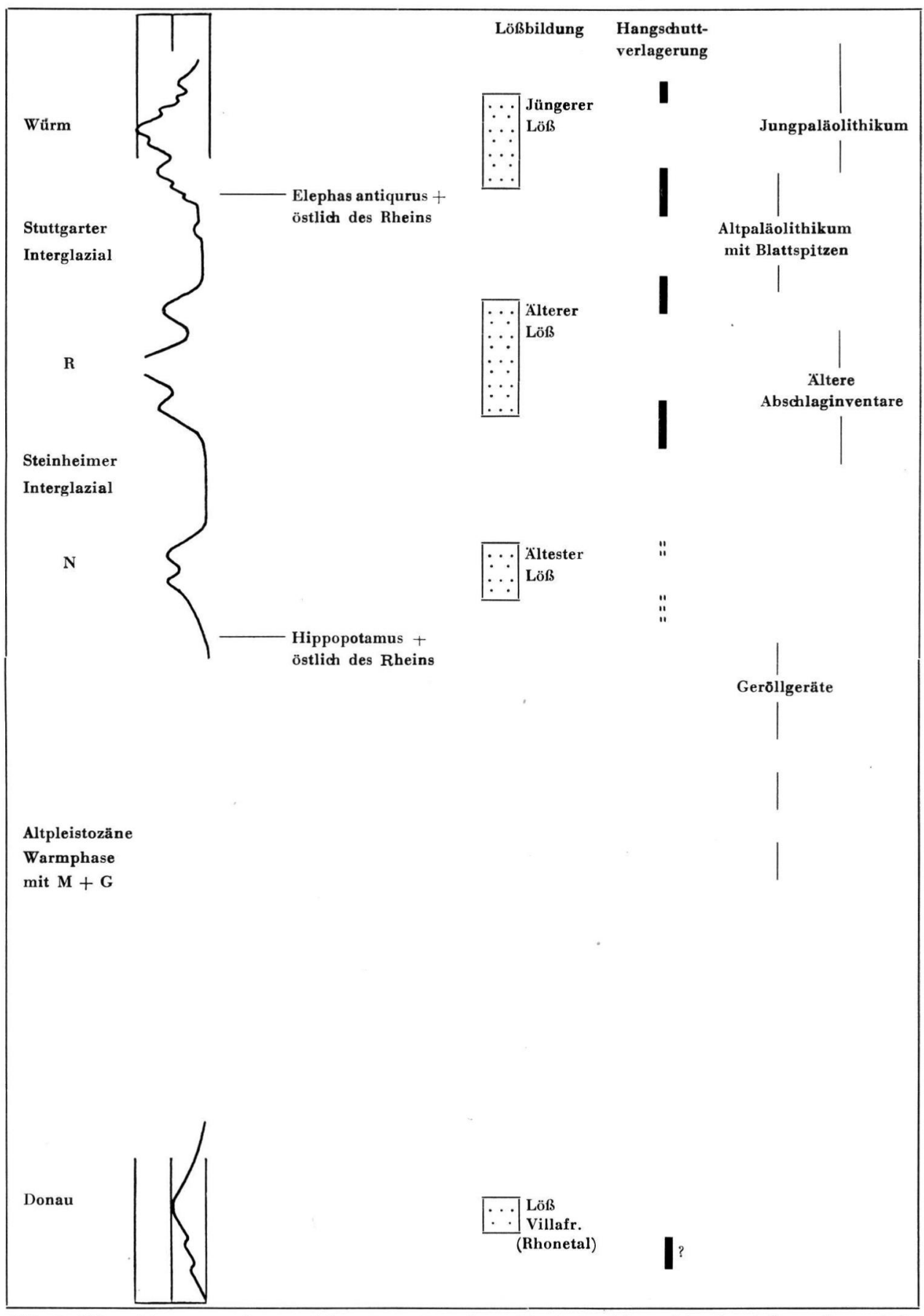

Abb. 5. Ubersichtsentwurf zur pleistozänen Stratigraphie in Süddeutschland. Links: schematische Klimakurve - Absinken der Durchschnittstemperatur = Ausschlag nach links. Verhältnis annähernd maßstäblich: 1. Linie $=$ hocharktisch, 2. Linie $=$ subarktisch, 3. Linie = gemäßigt-mild. Vertikal ohne einheitlichen Zeitmaßstab, Beginn von $\mathrm{N}$ aber kaum vor $250000 \mathrm{v}$. Chr. 
wicklung ihren Anfang genommen haben. Artefakte aus der folgenden Kaltzeit (N) fehlen wahrscheinlich grundsätzlich. In klimagünstigeren weiten Teilen der Alten Welt dürfte während dieser Zeit die endgültige Ablösung der frühpaläolithischen Geröllkulturen durch die ersten als altpaläolithisch zu bezeichnenden Gruppen erfolgen. Ebenso fehlen paläolithische Funde aus dem Steinheimer Interglazial. Eine Begehung Süddeutschlands wird aber wenigstens durch den Schädel von Steinheim belegt. Einfache altpaläolithische Inventare in altertümlicher Schlagtechnik erscheinen im Beginn und in einer größeren interstadialen Schwankung einer anschließenden Kaltzeit (R). Typologisch teilweise ähnliche, aber erheblich reichere Inventare aus dem klimagünstigeren Westeuropa besitzen eine gleichartige stratigraphische Stellung. Den Ausgang desselben Kaltzeit-Komplexes, beziehungsweise den Beginn des folgenden Interglazials (Stuttgart) kennzeichnen altpaläolithische Faustkeilschaberindustrien. Die ersten Blattspitzentendenzen tauchen in einem späteren Abschnitt des gleichen Interglazials auf. Außerordentlich vielgestaltig hingegen wird das späte Altpaläolithikum im Beginn der letzten Kaltzeit (Würm): neben Blattspitzen führenden Inventaren treten besonders kratzerreiche altpaläolithische Gruppen in den Vordergrund. Wenn auch die Diskordanz zwischen Alt- und Jungpaläolithikum in Süddeutschland vorläufig stratigraphisch nicht sicher erfaßbar ist, so sind doch die beiden durch die Hauptschwankung getrennten Würmabschnitte artefakttypologisch voneinander absetzbar. Das Untere Würm führt neben belegtem Altpaläolithikum möglicherweise bereits die ersten süddeutschen jungpaläolithischen Funde, während im Oberen Würm, ebenso wie in Westeuropa, das Altpaläolithikum völlig verschwunden ist und nur noch rein jungpaläolithische Inventare in Erscheinung treten. Das Spät- und Postglazial endlich wird von entwickelten jungpaläolithischen Gruppen und den anschließenden mesolithischen Spätstufen beherrscht.

\section{Literaturverzeichnis}

Adaм, K. D.: Die altpleistocänen Säugetierfaunen Südwestdeutschlands. - Neues Jb. Geol. Paläontol., Mh. 1952, S. 229-236. - - Die Bedeutung der altpleistozänen SäugetierFaunen Südwestdeutschlands für die Gliederung des Eiszeitalters. - Geol. Bavar. 19, S. 357-363, 1953 (1953 a). - - Faunenzusammenstellung. - Hektographiertes Kongreßmaterial. - 5. Hauptversammlung Deuqua, Stuttgart 1953 (1953 b). - - Die zeitliche Stellung der Urmenschen-Fundschicht von Steinheim an der Murr innerhalb des Pleistozäns. - Eiszeitalter und Gegenwart 4/5, S. 18-21, 1954.

Andree, J.: Der eiszeitliche Mensch in Deutschland und seine Kulturen. - Stuttgart 1939.

BANDI, H.-G.: Die Brügglihöhle an der Kohlholzhalde bei Nenzlingen (Kt. Bern), eine neue Fundstelle des Spätmagdalénien im unteren Birstal. - Jb. Bern. Hist. Mus. 32/33, S. 45-76, 1954.

Beck, P.: in: H. Graul: Tagung zum Studium schweizerischer Quartärfragen. - Eiszeitalter und Gegenwart 4/5, S. 233-235, 1954.

Becksmann, E.: Entstehung und Entwicklung der Mauerer Neckarschlinge. - Mitteilungsbl. Bad. Geol. LA 1949, 4 S., 1950.

Becksmann, E. \& RichteR, W.: Die ehemalige Neckarschlinge am Ohrsberg bei Eberbach in der oberpliozänen Entwicklung des südlichen Odenwaldes. - Sitzungsber. Heidelberg. Akad. Wiss., Math.-naturw. K1., 6 Abh., 1939.

Bercknemer, F.: Ein Menschen-Schädel aus den diluvialen Schottern von Steinheim a. d. Murr. - Anthropol. Anz. 10, S. 318-321, 1933. - - Belege für den diluvialen Menschen in der Untertürkheimer Gegend. - Untertürkheimer Heimatbuch, S. 105-106, 1935 (1935 a). - - Der Sauerwasserkalk von Untertürkheim und seine Fossileinschlüsse. - Ebendort, S. $11-24(1935 b)$.

Bohmers, A.: Die Höhlen von Mauern. Teil I. - Palaeohistoria 1, Groningen 1951.

Bordes, F.: Les limons quaternaires du Bassin de la Seine. - Arch. Inst. Paléont. Humaine, Mém. 26, Paris 1954.

Bordes, F. \& MüLler-BECK, Hj.: Zur Chronologie der Lößsedimente in Nordfrankreich und Süddeutschland. - Germania 34, S. 199-208, 1956.

Bourdier, F.: Pliocène et Quaternaire dans le bassin du Rhône. - Geol. Bavar. 19, S. 114-132, 1953. 
Breuil, H.: Les Subdivisions du Paléolithique supérieur et leur signification. - Congr. int. d' Anthropol. et Arch. Préhist., C.R. XIVe. sess. Bd. 1, S. 165-238, Genève 1912. - Les industries à éclats du Paléolithique ancien, I, Le Clactonien. - Préhistoire 1, S. $125-190,1932$ (1932a). - - Le Paléolithique ancien en Europe occidentale et sa chronologie. - Bull. Soc. préhist. franç. 33, S. 616-618, 1932 (1932b).

Breuil, H. \& Kelley, H.: Le Paléolithique ancien. - Bull. Soc. préhist. franç. 51, S. 1-26, 1954.

BrunNACKER, K.: Der würmzeitliche Löß in Bayern. - Geol. Bavar. 19, S. 258-265, 1953. - Die Höhlensedimente im Hohlen Stein bei Schambach. - Geol. B1. NO-Bayern 6, S. 21-32, 1956 (1956a). - - Regionale Bodendifferenzierung während der Würmeiszeit. - Eiszeitalter und Gegenwart 7, S. 43-48, 1956 (1956b).

EberL, B.: Die Eiszeitenfolge im nördlichen Alpenvorlande. - Augsburg 1930.

FrNK, J.: Zur Korrelation der Terrassen und Lösse in Österreich. - Eiszeitalter und Gegenwart 7, S. 49-77, 1956.

FraAs, O.: Die Ausgrabungen zu Schussenried. - Staatsanzeiger für Württemberg 249/250, 1866.

Freising, H.: Lösse, Fließerden und Wanderschutt im nördlichen Württemberg. - Diss. TH Stuttgart, 1949. - - Neue Ergebnisse der Lößforschung im nördlichen Württemberg. - Jh. geol. Abt. württembg. Stat. LA 1, S. 54-59, 1952. - - Exkursionen anläßlich der Tagung der Deuqua in Stuttgart. - Wegbeschreibung und Profilskizzen (hektographiert) 1953 (zit. n. J. FINK 1956). - - Steingeräte der mittleren Altsteinzeit aus Kleinheppach (Landkreis Waiblingen). - Eiszeitalter und Gegenwart 4/5, S. 87-97, 1954.

Freund, G.: Die Blattspitzen des Paläolithikums in Europa. - Bonn 1952. - - Die sedimentanalytischen Untersuchungen. In: L. F. Zorz 1955 (Mauern), S. 152-219.

Gams, H.: Die relative und absolute Chronologie des Quartärs. - Geol. Bavar. 19, S. 364-369, 1953.

Gerber, E.: Über Höhen-Schotter zwischen Emmetal und Aaretal. - Eclog. geol. Helv. 34, S. 1-16, 1941. - - Erläuterungen zu Blatt 22 des Geologischen Atlasses der Schweiz $1: 25$ 000. - Bern 1950.

Grahmann, R.: The Lower Palaeolithic site of Markkleeberg and other comparable localities near Leipzig. - Transact. Amer. Philosoph. Soc. N. S. 45, S. 509-687, 1955.

Graul, H.: Zur Gliederung des Altdiluviums zwischen Wertach/Lech und Flossach/Mindel. - Jb. naturforsch. Ges. Augsburg 2, S. 3-31, 1949. - - Tagung zum Studium schweizerischer Quartärfragen. - Eiszeitalter und Gegenwart 4/5, S. 233-235, 1954. - - Bemerkungen zu einer geologischen Übersichtskarte des Iller-Riß-Gebietes. - Z. deutsch.geol.Ges. 105, (1953), S. 517-524, 1955.

Graul, H. \& Schaefer, I.: Zur Gliederung der Würmeiszeit im Illergebiet. - Geol. Bavar. 18, München 1953.

Gross, H.: Weitere Beiträge zur Kenntnis des Spätglazials. - Eiszeitalter und Gegenwart 6, S. $110-115,1955$.

Gumpert, K.: Höhlengrabungen im Schambachtal. - Fränkische Landeszeitung 24. 11. 1952, Ansbach 1952. - - Neue erfolgreiche Grabung im "Hohlen Stein" bei Schambach. Heimgarten 44, Beilage der „Eichstätter Volkszeitung“" 1953.

Heller, F.: Die Fauna. In: L. F. Zotz 1955 (Mauern), S. 220-307.

Howell, F. C.: The age of the Australopithecines of Southern Africa. - Amer. Journ. physic. Anthropol. 13, S. 635-662, 1955.

KoKen, E.: Die Geologie und Tierwelt der paläolithischen Kulturstätten Deutschlands. In: R. R. SCHMidT 1912, S. 159-226.

Kraft, G.: Murg (Amt Säckingen), eine neue altpaläolithische Station. - Bad. Fundberichte 3, S. $316-321,1936$.

Kuss, S.: Die altpleistozänen Flußpferde des Oberrheingebietes. - Diss. Univ. Heidelberg 1955.

Leakey, L. S. B.: Adam's Ancestors, 4. Aufl. - London 1953.

Lehmann, U.: Eine Villafranchiano Fauna von der Erpfingerhöhle. - Neues Jb. Geol. Paläontol. Mineral. M.h. 1953, S. 437-464. - - Die Fauna des „Vogelherdes“ bei Stetten ob Lontal. - Neues Jb. Geol. Paläontol. Abh. 99, S. 33-146, 1954.

MÜLLER-BECK, $\mathrm{Hj}_{\text {.: }}$ Zur Datierung paläolithischer Kulturspuren im alpinen Bereich der Schweiz. - Jb. schweiz. Ges. Urgesch. 44, S. 161-180, 1954/55. - - Das Obere Altpaläolithikum in Süddeutschland. I. - Diss. Univ. Tübingen 1955, Hamburg 1956.

MüNNICH, K. O.: C14-Altersbestimmungen aus dem Zweiten Physikalischen Institut der Universität Heidelberg. - Liste 1 (hektographiert), Heidelberg 1956.

NARR, K. J.: Das Rheinische Jungpaläolithikum. Zugleich ein Beitrag zur Chronologie der späten Altsteinzeit Mittel- und Westeuropas. - Bonn 1955.

Obermaier, H.: Der Mensch der Vorzeit. - Berlin 1912.

Obermaier, H. \& Wernert, P.: Paläolithbeiträge aus Nordbayern. - Mitt. anthrop. Ges. Wien 44, S. 44-62, 1914. - - Alt-Paläolithikum mit Blattypen. - Mitt. anthrop. Ges. Wien 59, S. $293-310,1929$. 
Penck, A. \& BrüCkner, E.: Die Alpen im Eiszeitalter. - Leipzig 1901/09.

Peyrony, D.: Le Périgordien et l'Aurignacien. - Bull. Soc. préhist. franç. 33, S. 616-619, 1936. - - Le Périgordien, l'Aurignacien et le Solutréen en Eurasie d'après les dernières fouilles. - Ebendort 45, S. 305-328, 1948.

RiEK, G.: Die Eiszeitjägerstation am Vogelherd, Bd. 1. - Tübingen 1934. - - Kulturbilder aus der Altsteinzeit Württembergs. - Tübingen 1935. - - Ein Beitrag zur Kenntnis des süddeutschen Solutréen. - Germania 22, S. 147-150, 1938.

Riet Lowe, C. van: The development of the Hand-Axe Culture in South Africa. - Proceedings of the Pan-African Congress on Prehistory 1947, S. 167-177.

Roller, O.: Ein Beitrag zur Kenntnis des Magdalénien in Südwestdeutschland. - Festschrift für Peter Goessler, S. 142-149, Stuttgart 1953.

Rust, A.: Die Höhlenfunde von Jabrud (Syrien). - Neumünster 1950. - - Artefakte aus der Zeit des Homo heidelbergensis in Süd- und Norddeutschland. - Bonn 1956 (1956a). - Uber neue Artefaktfunde aus der Heidelberger Stufe. - Eiszeitalter und Gegenwart 7, S. 179-192, 1956 (1956b).

Schatfer, I.: Die donaueiszeitlichen Ablagerungen an Lech und Wertach. - Geol. Bavar. 19, S. 13-64, 1953.

Schмid, E.: Ưber den untersten Teil des Lößprofiles von Murg. - Mittbl. Bad. Geol. LA 1950, S. $95-97,1951$.

Schmidt, R. R.: Die diluviale Vorzeit Deutschlands. - Stuttgart 1912.

Schoetensack, O.: Der Unterkiefer des Homo Heidelbergensis - Leipzig 1908.

SOERGEL, W.: Die geologische Entwicklung der Neckarschlinge von Mauer. Ein Exkursionsbericht. - Paläontol. Ztschr. 15, S. 322-341, 1933.

Stehlin, H. G.: Revision der Säugetierfunde aus Hochterrasse und aus Ablagerungen der größten Vergletscherung. - Eclog. geol. Helv. 17, S. 364-377, 1922.

Tode, A.: Die Untersuchung der paläolithischen Freilandstation von Salzgitter-Lebenstedt. 8. Archäologische Erkenntnisse. - Eiszeitalter und Gegenwart 3, S. 192-215, 1953.

Vértes, L.: Die Höhle von Istállóskő. - Act. Archaeol. Acad. Scient. Hungaricae 5, S. 111-291, 1955.

Viret, J.: La faune de mammifères du loess durci de Saint-Vallier (Drôme) et ses conséquences stratigraphiques. - C. R. Séanc. Acad. Scienc. Paris 227, S. 684-686, 1948.

WeIdenbaCH, F.: Gedanken zur Lößfrage. - Eiszeitalter und Gegenwart 2, S. 25-36, 1952.

WETZEL, R.: Die Lonetalarbeit als Gemeinschaftsforschung. - Jber. wiss. Akad. Tübingen NSDDozentenbd. 1, S. 79-93, 1940. - - Quartärforschung im Lonetal. - Eiszeitalter und Gegenwart 4/5, S. 106-141, 1954.

Wiegers, F.: Diluviale Vorgeschichte des Menschen. Bd. 1. - Stuttgart 1928.

ZINK, F.: Zur diluvialen Geschichte des Hochrheins und zur Altersstellung der paläolithischen Station „Murg“. - Mitt. Reichsst. Bodenforschung, Zweigstelle Freiburg/Br. 1, 1940.

Zotz, L. F.: Altsteinzeitkunde Mitteleuropas. - Stuttgart 1951. - - Das Paläolithikum in den Weinberghöhlen bei Mauern. - Bonn 1955.

Manuskr. eingeg. 25. 1. 1957.

Anschrift des Verf.: Dr. Hansjürgen Müller-Beck, Bern (Schweiz), Schönauweg 12. 